\title{
Role of atazanavir in the treatment of HIV infection
}

\author{
Pablo Rivas' \\ Judit Morello² \\ Carolina Garrido' \\ Sonia Rodríguez-Nóvoa ${ }^{2}$ \\ Vincent Soriano' \\ 'Department of Infectious Diseases; \\ ${ }^{2}$ Pharmacology Unit, Hospital Carlos \\ III, Madrid, Spain
}

\begin{abstract}
Atazanavir (ATV) is one of the latest protease inhibitors (PI) approved for the treatment of HIV infection. The drug has a relatively long-life $(\sim 7 \mathrm{~h})$ and large inhibitory quotient which allows once daily administration. It is generally well tolerated and the main side effect is hyperbilirubinemia, since ATV inhibits the hepatic uridin-glucoronyl-transferase. A signature mutation at the protease gene, I50L, may confer loss of susceptibility to the drug. Interestingly, it produces hypersusceptibility to all other PIs. When ATV is pharmacokinetically boosted with ritonavir (r) $100 \mathrm{mg}$ /day, a greater genetic barrier for resistance is achieved, and generally more than 3 major PI resistance associated mutations are needed to result in ATV resistance. In drugnaïve subjects, regimens based on ATV/r have shown non-inferiority compared to lopinavir (LPV)/r (CASTLE study) or fosamprenavir/r (ALERT trial), generally with improved tolerance (less diarrhea and dyslipidemia). Given its good tolerance and convenience, ATV has been proven to be successful as a simplification strategy in switch studies (ie, SWAN and SLOAT) conducted in patients with complete virological suppression under other PI-based regimens. Finally, ATV/r-based combinations have shown to be equivalent in terms of viral response to other PI/r-containing regimens, including LPV/r, in rescue interventions in patients failing other PI regimens (ie, studies AI424-045 and NADIS).
\end{abstract}

Keywords: atazanavir, HIV, protease inhibitors, drug resistance

\section{Introduction}

The introduction of triple combination therapy following the availability of protease inhibitors (PIs) dramatically changed the natural history of HIV infection in the late 1990s. When the first PI (saquinavir) was marketed in 1995, the recognition of significant gains in CD4 counts and dramatic reductions in the incidence of opportunistic events accompanying by unprecedent declines in virus replication produced a huge enthusiasm in both patients and clinicians. However, this initial joy was soon tempered when patients began to complain of difficulties in pursuing treatment schedules and especially when side effects became clearly manifest. Even worse was the recognition that disturbances in the metabolism of lipids and glucose and disfiguring morphological features due to fat tissue redistribution were a new stigmatizing feature following prolonged PI exposure.

A new generation of PI compounds free of the main limitations of the first-generation PIs has recently entered the HIV armamentarium. ATV, marketed as Reyataz ${ }^{\circledR}$ (BristolMyers Squibb), may have an advantage over other PIs because of its favorable effect on lipid profiles, once-daily dosing, low capsule burden and a relatively favorable resistance profile. ${ }^{1}$ This article reviews the main pharmacologic and clinical features of ATV and updates its role in the treatment of HIV infection.

\section{Mechanism of action}

ATV is an azapeptide inhibitor of the HIV-1 protease. The chemical name for ATV sulfate is (3S,8S,9S,12S)-3,12-bis(1,1-dimethylethyl)-8-hydroxy-4,11-dioxo-9-(phenylmethyl)6-((4-(2-pyridinyl)phenyl)methyl)-2,5,6,10,13-pentazatetradecanedioic acid dimethyl ester sulfate (1:1) (Figure 1). The compound inhibits the virus-specific processing of viral Gag and Gag-Pol poliproteins of HIV-1 group $\mathrm{M}$ subtype A, B, C, D, AE, AG, 


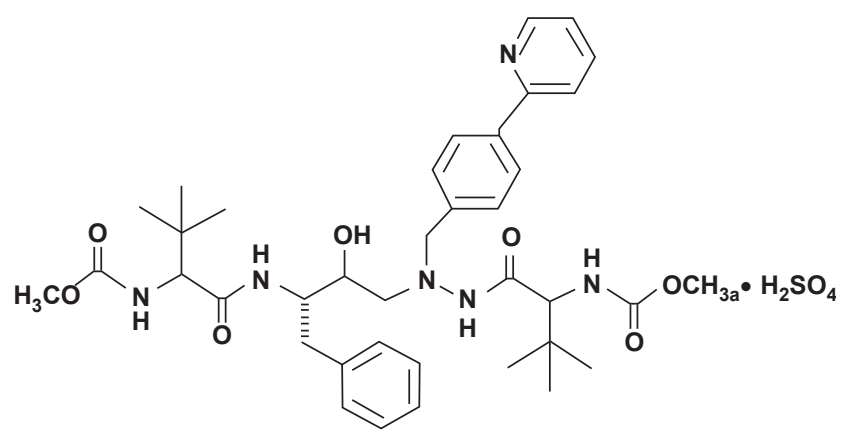

Figure I Chemical structure of atazanavir sulfate.

$\mathrm{F}, \mathrm{G}$, and $\mathrm{J}$ in infected cells, thus preventing formation of mature virions. ${ }^{1}$ As measure of potency, the concentration that inhibits $50 \%$ of viral replication (IC50) in the absence of human serum ranged from $0.58 \mathrm{ng} / \mathrm{mL}$ to $5.7 \mathrm{ng} / \mathrm{mL}$ in a panel of susceptible viruses isolated from 31 PI-naïve HIV-infected patients. ${ }^{2,3}$ The presence of $40 \%$ human serum in cell cultures increased ATV IC50 by 2.7- to 3.6-fold, as noticed for other PIs. The adjusted IC50 for protein binding was estimated to range from 8 to $20 \mathrm{ng} / \mathrm{mL}$ against reference viral strains with a conventional cycle cell infection and the PhenoSense ${ }^{\mathrm{TM}}$ single assay (ViroLogic Inc., South San Francisco, CA, USA), respectively. ${ }^{2}$

\section{Drug resistance}

Resistance patterns to ATV differ according to the population exposed to the drug being PI-naïve or -experienced, and to ritonavir (r) boosting. The presence of a single major mutation in the protease gene may result in loss of susceptibility to ATV, but in clinical practice ATV resistance generally occurs when several mutations in the protease gene are present. In PI-naïve patients, the most frequent mutation at failure under ATV is I50L, ${ }^{4,5}$ while in PI-experienced patients mutations I84V and N88S are more commonly selected. Of note, I50L is only selected under ATV pressure and it causes higher susceptibility to other PIs such as amprenavir, darunavir, indinavir, lopinavir (LPV), nelfinavir (NFV) and saquinavir (SQV). ${ }^{6}$ The prevalence of I50L in large HIV drug resistance mutation databases is generally very low. ${ }^{7}$

ATV is almost always prescribed boosted with $r$, but the Food and Drug Administration (FDA) allows also its use unboosted in selected PI-naïve patients and in simplification strategies. In contrast, the EMEA has not approved yet the use of ATV without $r$ boosting. When PIs are used without $r$ boosting, drug exposures are significantly lower. In this situation, the resistance barrier may be confined to a single key mutation (eg, I50L).
Interpretation of drug resistance mutations is complicated. First, a qualitative approach is usually performed identifying changes that could affect drug susceptibility. As not all changes in the protease gene have the same influence on drug susceptibility, a quantitative score giving different weight to each mutation and each drug must be used. The International AIDS Society-USA (IAS-USA) Panel describes a list of mutations in the protease gene that are associated with resistance to ATV. This list include changes at positions $10,16,20,24,32,33,34,36,46,48,50,53,54,60,62,64$, $71,73,82,84,85,88,90$ and 93 , although the only changes considered as major mutations are I50L, I84V and N88S. ${ }^{8}$ Table 1 records different algorithms developed to assist in the interpretation of resistance to ATV.

The accumulation of multiple PI resistance mutations has been shown to be a major indicator of ATV loss of susceptibility. In vitro analysis of the genotypic profiles of 943 PI-susceptible and PI-resistant clinical isolates identified a strong correlation between the presence of several amino acid changes at specific residues $(10 \mathrm{I} / \mathrm{V} / \mathrm{F}, 20 \mathrm{R} / \mathrm{M} / \mathrm{I}, 24 \mathrm{I}, 33 \mathrm{I} / \mathrm{F} / \mathrm{V}, 36 \mathrm{I} / \mathrm{L} / \mathrm{V}, 46 \mathrm{I} / \mathrm{L}, 48 \mathrm{~V}$, 54V/L, 63P, 71V/T/I, 73C/S/T/A, 82A/F/S/T, 84V, and 90M) and decreased susceptibility to ATV. ${ }^{2}$ In addition, data from PI-experienced patients revealed that the median number of PI-associated resistance mutations was lower in patients showing virological response than in non-responders. ${ }^{9}$

As with other PIs, failure of ATV is often rather better explained by lack of potency than by the acquisition of primary resistance mutations, especially in patients without previous PI failure. ${ }^{10}$ In PI-experienced patients, the genotypic inhibitory quotient (GIQ) has been proven to be a good predictor of virological response to ATV, as it integrates both resistance mutations and drug plasma exposure. ${ }^{9}$

\section{Cross-resistance}

Although there is no obvious overlapping resistance pattern of ATV with any other particular PI, cross-resistance with ATV is observed in isolates resistant to 4 or more PIs. ${ }^{2}$ The NADIS French study proved that ATV/r-based rescue therapy is generally efficient in most PI-experienced patients, except in those who had failed an LPV/r-containing regimen. ${ }^{11} \mathrm{By}$ contrast, mutation L76V, selected under virologic failure with other PIs, produces hypersusceptibility to ATV. ${ }^{12}$

\section{Resistance to atazanavir in HIV-I non $B$ subtypes and in HIV-2}

HIV variants other than subtype B show a high genetic variability within the protease, presenting many polymorphisms at positions associated with PI resistance in subtype B. 
Table I Different genotypic resistance scores for atazanavir (boosted or unboosted) in relation to clinical responses

\begin{tabular}{|c|c|c|c|}
\hline Source & Protease inhibitor & Protease mutations & Clinical cut-off \\
\hline Colonno et $\mathrm{al}^{2}$ & Atazanavir & $\begin{array}{l}\mathrm{LIOF/I/V,} \mathrm{K20I/M/R,} \mathrm{L24I,} \mathrm{L33F/I/V,} \mathrm{M36I/L/V,} \mathrm{M46I/L,} \mathrm{G48V,} \mathrm{I54L/V,} \mathrm{L63P,} \mathrm{A7II/} \\
\mathrm{V} / \mathrm{T}, \mathrm{G} 73 \mathrm{~A} / \mathrm{C} / \mathrm{S} / \mathrm{T}, \mathrm{V} 82 \mathrm{~A} / \mathrm{F} / \mathrm{T} / \mathrm{S}, \mathrm{8} 4 \mathrm{~V}, \mathrm{~L} 90 \mathrm{M} \text {, or the presence of I50L alone }\end{array}$ & $<$ versus $\geq 4$ \\
\hline $\begin{array}{l}\text { ANRS } 2004 \\
\text { www.sante.gouv.fr }\end{array}$ & Atazanavir-ritonavir & $\begin{array}{l}\mathrm{LI} \text { OF/I/V, K20I/M/R, L24I, L33F//V, M36I/L/V, M461/L, G48V, I54L/V, L63P, A7II/ } \\
\mathrm{V} / \mathrm{T}, \mathrm{G} 73 \mathrm{~A} / \mathrm{C} / \mathrm{S} / \mathrm{T}, \mathrm{V} 82 \mathrm{~A} / \mathrm{F} / \mathrm{T} / \mathrm{S}, \mathrm{184V}, \mathrm{L} 90 \mathrm{M} \text {, or the presence of I50L alone }\end{array}$ & $<$ versus $\geq 6$ \\
\hline ANRS $2005^{82}$ & Atazanavir-ritonavir & $\begin{array}{l}\mathrm{LIOF} / \mathrm{I} / \mathrm{V}, \mathrm{GI} 6 \mathrm{E}, \mathrm{L} 33 \mathrm{~F} / \mathrm{I} / \mathrm{V}, \mathrm{M} 461 / \mathrm{L}, \mathrm{D} 60 \mathrm{E}, 184 \mathrm{~V}, 185 \mathrm{~V}, \mathrm{~L} 90 \mathrm{M} \text {, or the presence } \\
\text { of I50L alone }\end{array}$ & $<$ versus $\geq 3$ \\
\hline Pellegrin et $\mathrm{al}^{26}$ & Atazanavir-ritonavir & $\begin{array}{l}\mathrm{LIOF} / \mathrm{I} / \mathrm{V}, \mathrm{K} 20 \mathrm{I} / \mathrm{M} / \mathrm{R}, \mathrm{L} 24 \mathrm{I}, \mathrm{M} 46 \mathrm{I} / \mathrm{L}, \mathrm{I54L} / \mathrm{V}, \mathrm{Q} 58 \mathrm{E}, \mathrm{L} 63 \mathrm{P}, \mathrm{A} 7 \mathrm{II} / \mathrm{V} / \mathrm{T}, \mathrm{G} 73 \mathrm{~A} / \mathrm{C} / \mathrm{S} / \mathrm{T} \text {, } \\
\mathrm{V77I}, \mathrm{V} 82 \mathrm{~A} / \mathrm{F} / \mathrm{T} / \mathrm{S}, 184 \mathrm{~V}, \mathrm{~L} 90 \mathrm{M} \text {, or the presence of I50L alone }\end{array}$ & $<$ versus $\geq 5$ \\
\hline Bertoli et al ${ }^{83}$ & Atazanavir & $\begin{array}{l}\mathrm{L} 10 \mathrm{C} / \mathrm{I} / \mathrm{V}, \mathrm{V} 32 \mathrm{I}, \mathrm{E} 34 \mathrm{Q}, \mathrm{M} 461 / \mathrm{L}, \mathrm{F} 53 \mathrm{~L}, 154 \mathrm{~A} / \mathrm{M} / \mathrm{V}, \mathrm{V} 82 \mathrm{~A} / \mathrm{F} / \mathrm{I} / \mathrm{T}, \mathrm{I84V}, \mathrm{II} 5 \mathrm{E} / \mathrm{G} / \mathrm{L} / \mathrm{V} \\
\mathrm{H} 69 \mathrm{~K} / \mathrm{M} / \mathrm{N} / \mathrm{Q} / \mathrm{R} / \mathrm{T} / \mathrm{Y}, 172 \mathrm{M} / \mathrm{T} / \mathrm{V}\end{array}$ & $<$ versus $\geq 4$ \\
\hline Bertoli et al ${ }^{83}$ & Atazanavir-ritonavir & GI6E,V32I, K20I/M/R/T/V, L33F/I/V, F53L/Y, I64L/M/V, A7II/T/V, I85V, 193L/M & $<$ versus $\geq 3$ \\
\hline
\end{tabular}

Abbreviation: ANRS, agence nationale de recherche sur le sida et les hépatites Virales.

Nevertheless, primary resistance mutations do not appear as natural polymorphisms to ATV either in HIV-1 non-B subtypes or in HIV-2 isolates. Indeed, 48-week data from the CASTLE study have confirmed that virologic response to ATV is independent from HIV subtype. ${ }^{13}$

\section{Pharmacokinetics}

ATV is rapidly absorbed with a peak plasma concentration $\left(\mathrm{C}_{\max }\right)$ occurring at approximately 2.5 hours and demonstrates non-linear pharmacokinetics. The extent of absorption is highly dependent on gastric $\mathrm{pH}$ and increases when taken together with a light meal. ATV is $86 \%$ bound to human serum proteins to both alpha-1-acid glycoprotein and albumin to a similar extent. ATV is a substrate for P-glycoprotein (P-gp), an efflux transporter that will act to limit tissue compartment distribution. Like other PIs, ATV is extensively metabolized by hepatic cytochrome P450, primarily the CYP3A4/CYP3A5 isoenzymes. ATV and its metabolites then undergo biliary and urinary excretion for $79 \%$ and $13 \%$ of an administered dose, respectively. Unchanged drug accounts approximately for $20 \%$ and $7 \%$ of the administered dose in feces and urine, respectively. Steady-state is achieved between days 4 and 8 , with an accumulation of approximately 2.3 -fold. Finally, ATV scarcely enters the cerebrospinal fluid (CSF) and semen, with a CSF/plasma ratio ranging between 0.0021 and 0.0226 and a seminal fluid/plasma ratio ranging from 0.11 to $4.42 .{ }^{1}$

A strategy to enhance PI pharmacokinetic parameters consists of the co-administration of low doses of $r$ (boosting). As $r$ is a potent inhibitor of CYP3A and to a less extent of P-gp, co-administration of ATV and low doses of $\mathrm{r}(100 \mathrm{mg} /$ day $)$ result in a decrease in ATV gastrointestinal clearance and first-pass hepatic effect. Consequently, ATV normal half-life $(\sim 7 \mathrm{~h})$ is increased resulting in higher minimum concentration $\left(\mathrm{C}_{\min }\right), \mathrm{C}_{\max }$ and AUC. ${ }^{1}$ Table 2 depicts the main pharmacokinetic parameters of ATV 400 and ATV/r $300 / 100 \mathrm{mg} /$ day. ${ }^{1,14}$

There is large inter-individual variability in ATV disposition. In a population pharmacokinetic study which included 214 HIV patients, multiple factors that potentially could influence the variability of ATV pharmacokinetics were assessed, including body weight, sex, ethnicity, creatinine clearance, and concomitant medications ( $r$, nevirapine, tenofovir, abacavir, lamivudine and proton pump inhibitors). Only body weight, $r$ and nevirapine appeared to be highly correlated with ATV clearance. ${ }^{15}$

\section{Pharmacokinetics in special populations Pediatric}

ATV has not been fully evaluated in pediatric patients and the optimal dosage has not been established. In the phase I/II

Table 2 Pharmacokinetic parameters at steady state after atazanavir $400 \mathrm{mg}$ once daily and after atazanavir $300 \mathrm{mg}$ with ritonavir $100 \mathrm{mg}$ once daily with a light meal in HIV-infected patients

\begin{tabular}{lll}
\hline & ATV $400 \mathbf{~ m g}$ & ATV/r 300/I 00 mg \\
\hline Bioavailability (\%) & 68 & Not available \\
Protein binding (\%) & 86 & 86 \\
Distribution volume & Not available & Not available \\
Clh $(\mathrm{L} / \mathrm{h})$ & 25.2 & Not available \\
Clr of parent drug (\%) & 7 & Not available \\
$\mathrm{t}_{\mathrm{I} / 2}$, mean $\pm \mathrm{SD}(\mathrm{h})$ & $6.5 \pm 2.6$ & $8.6 \pm 2.3$ \\
$\mathrm{C}_{\text {max }}$, mean $\pm \mathrm{SD}(\mathrm{ng} / \mathrm{mL})$ & $3152 \pm 223 \mathrm{I}$ & $5233 \pm 3033$ \\
$\mathrm{~T}_{\text {max }}$, median $(\mathrm{h})$ & 2 & 3 \\
$\mathrm{C}_{\text {min }}$, mean $\pm \mathrm{SD}(\mathrm{ng} / \mathrm{mL})$ & $273 \pm 298$ & $862 \pm 838$ \\
AUC, mean $\pm \mathrm{SD}(\mathrm{ng} / \mathrm{mL} / \mathrm{h})$ & $22262 \pm 20159$ & $5376 \mathrm{I} \pm 35294$ \\
\hline
\end{tabular}

Abbreviations: ATV, atazanavir; RTV, ritonavir; Clh, hepatic clearance; Clr, renal clearance; $\mathrm{T}_{1 / 2}$, half-life; $\mathrm{C}_{\max }$, maximum concentration; $\mathrm{T}_{\max }$, time at $\mathrm{C}_{\max } ; \mathrm{C}_{\text {min }}$, minimum concentration; AUC, area under the curve. 
PATCG 1020A study, ATV was dosed at $310 \mathrm{mg} / \mathrm{m}^{2}$ body surface area and adjusted over $24 \mathrm{~h}$ in 172 children with a mean age of 1.2 years up to 17 years. AUC presented a wide range between $33,800 \mathrm{ng} / \mathrm{mL} / \mathrm{h}$ in infants with a mean age of 1.2 years and $67,100 \mathrm{ng} / \mathrm{mL} / \mathrm{h}$ in children with a mean age of 15 years. The $\mathrm{C}_{\max }$ values were $3900 \mathrm{ng} / \mathrm{mL}$ in adolescents (mean age, 17 years) and $7400 \mathrm{ng} / \mathrm{mL}$ in the youngest children (mean age, 1.2 years). ${ }^{16}$

\section{Hepatic impairment}

Although few data have been derived from HIV patients with severe hepatic dysfunction, an increased exposure to the drug in such individuals is anticipated. In non-HIV infected adults with moderate to severe hepatic impairment, $\mathrm{AUC}_{(0-\infty)}$ was increased in $42 \%$ after a single 400-mg dose compared with healthy volunteers. On the basis on these data, a dose reduction of ATV is advised for patients with moderate hepatic dysfunction. ${ }^{1}$ In contrast, in a study conducted in $58 \mathrm{HCV} / \mathrm{HIV}$-coinfected patients with compensated liver disease, ATV $_{\text {min }}$ did not differ significantly between patients with and without liver cirrhosis. ${ }^{17}$

\section{Renal impairment}

ATV pharmacokinetics have been evaluated in 20 adults with severe renal impairment, including a few on hemodialysis, using multiple doses of $400 \mathrm{mg}$ once daily. The mean ATV $\mathrm{C}_{\max }$ was $9 \%$ lower, AUC was $19 \%$ higher, and $\mathrm{C}_{\min }$ was $96 \%$ higher in subjects with severe renal impairment not undergoing hemodialysis, than in subjects with normal renal function. When ATV was administered either before or after hemodialysis, the geometric means for $\mathrm{C}_{\max }, \mathrm{AUC}$, and $\mathrm{C}_{\min }$ were approximately $25 \%$ to $43 \%$ lower compared to subjects with normal renal function. No dose adjustment is required in patients who are not managed with hemodialysis and HIV patients with end stage renal disease managed with hemodialysis should receive ATV 300 with r $100 \mathrm{mg}$ daily. ATV should not be administered to antiretroviralexperienced patients with end stage renal disease managed with hemodialysis. ${ }^{1}$

\section{Pregnancy}

Although there are no adequate pharmacokinetic studies in pregnant women, data from other PIs suggest a decrease in plasma exposure during the third trimester. ${ }^{18}$ A pharmacokinetic study was performed in $12 \mathrm{HIV}$-pregnant women receiving ATV/r 300/100 mg/day. The third trimester AUC and $\mathrm{C}_{\min }$ were approximately $40 \%$ and $21 \%$ lower, respectively, than in adult HIV-infected patients. All subjects reaching delivery achieved plasma HIV-RNA $<50$ copies/mL and all infants tested were HIV-negative and presented normal bilirubin values through day 14 . However, 1 newborn developed grade 3 hyperbilirubinemia at day $15 .{ }^{19}$ In another study, total bilirubin concentrations were above normal limits at birth and day 3, and 3 newborns had transient neonatal jaundice which did not require phototherapy. ${ }^{20}$

\section{Drug interactions}

ATV is a substrate and inhibitor of CYP3A ( $\mathrm{Ki}$ value of 0.84 to $1.0 \mu \mathrm{M})$. ATV also inhibits CYP2C8 $(\mathrm{Ki}=2.1 \mu \mathrm{M})$ and UGT1A1 $(\mathrm{Ki}=1.9 \mu \mathrm{M})$. It is also a substrate and inhibitor of P-gp with levels comparable to verapamil, a well known P-gp inhibitor. ${ }^{21,22}$ Therefore, co-administration of ATV and drugs primarily metabolized by CYP3A, CYP2C8, or UGT1A1 and/or substrates of P-gp may result in increased plasma concentrations of the concomitant drug, which potentially could enhance or prolong both their therapeutic and adverse effects. The magnitude of the mediated drug interaction may change when ATV is co-administered with $r$. On the other hand, drugs that induce CYP3A4 and/or P-gp may decrease ATV plasma concentrations and therefore compromise ATV therapeutic effect. Finally, drugs affecting the gastric $\mathrm{pH}$ may alter ATV solubility and consequently its bioavailability. ${ }^{1}$ ATV and ATV/r drug interactions are summarized in Table 3.

As shown in Figure 2, raltegravir, the first integrase inhibitor approved for the treatment of HIV infection, is metabolized by glucuronidation, but interactions with ATV do not generally result in increased hyperbilirubinemia since different UGT isoenzymes are subject to ATV inhibition and raltegravir metabolism, respectively.

\section{Therapeutic drug monitoring (TDM)}

Monitoring plasma drug concentrations has proven to be useful for PIs, and may allow tailoring of antiretroviral therapy. ${ }^{23}$ ATV plasma concentrations demonstrate high inter-individual variability, even in the presence of $r$, along with a low intra-individual variability, supporting TDM. The definition of a therapeutic range for ATV concentrations has been pursued for a while in an attempt to minimize side effects, mainly hyperbilirubinemia while ensuring maximal efficacy, especially when $r$ unboosted ATV needs to be used. ${ }^{24}$

\section{Atazanavir plasma concentrations as predictors of virological response}

Several studies have evaluated the relationship between ATV plasma levels and virological response. ${ }^{9,25,26}$ A threshold of $0.15 \mathrm{mg} / \mathrm{L}$ has been proposed for antiretroviral-naïve patients based on results of a retrospective study performed 
on 51 patients. In that study, virological responses according to ATV trough concentrations $\left(\mathrm{C}_{\text {trough }}\right)$ were as follows: $58.3 \%$ when $<0.15 \mathrm{mg} / \mathrm{L}, 75 \%$ when values between 0.15 and $0.85 \mathrm{mg} / \mathrm{L}$, and $100 \%$ when $>0.85 \mathrm{mg} / \mathrm{L}^{25}$

In PI-experienced patients, the combined use of pharmacokinetics and resistance information has been proposed as a better predictor of virological response than use of these two variables separately. ${ }^{27,28}$ The genotypic inhibitory quotient (GIQ), defined as the ratio of the minimum plasma drug concentration to the number of resistance mutations in the protease gene, has been associated with virological response to ATV in PI-experienced patients..$^{9,25,26}$ A GIQ $>0.10 \mathrm{mg} / \mathrm{L}$ mutation has been found to significantly predict virological response at 24 weeks. Mutations more significant to be included in the GIQ model are the following: L10F/I/V, K20M/R, L24I, D30N, V32I, L33F, M36I/L, I47V/A, G48V, I50V, I50L, F53L, I54V/L/A/M/T/S, L63P, A71V/T, G73S, V77I, V82A/F/T, I84V, N88D/S and L90M. ${ }^{25}$

\section{Atazanavir plasma levels as predictors of hyperbilirubinemia}

Several studies have found an association between ATV plasma concentrations and serum bilirubin levels. ${ }^{9,25,29,30}$ However, at this time there are not enough data available to define threshold for scleral jaundice, which otherwise may vary from one subject to another, although it can generally be recognized when serum bilirubin goes up $2.5 \mathrm{mg} / \mathrm{dL}$.

In HIV-HCV-coinfected patients on stable ATV therapy who begin treatment with pegylated interferon plus ribavirin, hemolytic anemia caused by ribavirin may result in increased levels of bilirubin (Figure 2). In a study performed in 72 $\mathrm{HCV} / \mathrm{HIV}$-coinfected patients treated for hepatitis $\mathrm{C}$, up to $45 \%$ of those on ATV experienced serum bilirubin increases greater than $1 \mathrm{mg} / \mathrm{dL}$ compared with only $3 \%$ of individuals under other antiretroviral regimens. Indeed, the proportion of patients on ATV who experienced hyperbilirubinemia grade 3-4 increased 2.5-fold after beginning hepatitis $\mathrm{C}$ therapy (from $9 \%$ to $45 \%$ ). ${ }^{31}$

Another population in which TDM for ATV may be particularly useful is the subset of HIV patients treated concomitantly with TDF, the most widely used antiretroviral agent. The co-administration of ATV and TDF results in a $20 \%$ to $40 \%$ reduction in ATV plasma concentrations. ${ }^{1,32}$ Therefore, the current advice is to give ATV boosted with low doses of $r$ when taken along with TDF. However, this intervention may be regarded as less convenient for drugnaïve subjects because of the need for an additional extra pill of $r$, which has to be kept in the refrigerator and often produces gastrointestinal disturbances. More importantly, it increases the risk of jaundice and eliminates the lipid-friendly behavior of ATV. ${ }^{33}$ In a retrospective study performed in 56 HIV patients with undetectable plasma HIV-RNA under a triple regimen containing ATV/r 300/100 mg once daily (qd), TDM was useful to allow a switch to ATV $400 \mathrm{mg}$ qd. A total of $79 \%$ were taking concomitantly TDF. At week 24 , therapeutic levels $\left(\mathrm{C}_{\text {trough }}>150 \mathrm{ng} / \mathrm{mL}\right)$ were kept in all patients but 4 . TDF was part of the antiretroviral regimen in all 4 cases. From a total of 29 (52\%) patients on ATV/RTV showing grade 3-4 hyperbilirubinemia, only 7 (12\%) still suffered from it upon switching to ATV $400 \mathrm{mg}$ qd. Undetectable viral load was maintained in all patients but one in whom subtherapeutic ATV concentrations were seen. Therefore, TDM can be a useful tool to identify the subset of ATV treated patients in whom removal of $r$ could be attempted without risk of suboptimal plasma ATV exposure and subsequent virological failure. ${ }^{34}$

\section{Pharmacogenetics}

Hyperbilirubinemia is the most common adverse effect in patients treated with ATV. The underlying mechanism is an inhibition by ATV of the uridine-glucuronosyl-transferase (UGT) $1 \mathrm{~A} 1$ enzyme, which is involved in bilirubin conjugation (Figure 2) ${ }^{35,36}$ In this context, genetic factors affecting ATV disposition and/or UGT1A1 function could alter bilirubin levels.

Several single nucleotide polymorphisms (SNP) with potential consequences in the expression of $\mathrm{P}$-gp have been identified in the gene that codifies for P-gp, named multidrug resistance gene 1 (MDR1). In patients taking ATV $400 \mathrm{mg}$ qd, the $3435 \mathrm{C}>\mathrm{T}$ polymorphism has been associated with lower ATV plasma levels and lower serum bilirubin levels. ${ }^{29}$ Accordingly, the risk for developing severe hyperbilirubinemia was as high as $24 \%$ in subjects with MDR1 wild-type alleles but as low as $0 \%$ in those homozygous for the $3435 \mathrm{C}>\mathrm{T}$ polymorphism. These results have been confirmed thereafter in patients on ATV/RTV, as patients with the CC genotype show significantly higher median ATV $\mathrm{C}_{\text {trough }}$ concentrations than those with CT/TT genotypes (939 versus $376 \mathrm{ng} / \mathrm{mL}$, respectively). ${ }^{30}$ The $\mathrm{C} 3435 \mathrm{~T}$ polymorphism is a silent change and thus it is unlikely that it directly influences the expression of the MDR1 gene. ${ }^{37}$ Most likely, this polymorphism may be linked to one or more other unidentified changes in MDR1 or distinct metabolizing enzyme genes. The $2677 \mathrm{G}>\mathrm{T}$ polymorphism has recently been suggested as the possible candidate. ${ }^{38}$ Persons homozygous for the MDR1 2677T allele, which is frequently linked to the $3435 \mathrm{~T}$ allele, show enhanced 
Table 3 Main drug interactions with atazanavir $400 \mathrm{mg}$ or atazanavir/ritonavir 300/100 mg/day

\begin{tabular}{|c|c|c|c|}
\hline Family & Drug & Effect on concentration & Recommendation \\
\hline Antiarrhythmics & $\begin{array}{l}\text { amiodarone, bepridil, } \\
\text { lidocaine, quinidine }\end{array}$ & $\uparrow$ antiarrhythmic & Caution is warranted,TDM recommended. \\
\hline Anticoagulants & warfarin & $\uparrow$ warfarin & Monitoring of INR is recommended. \\
\hline Anticonvulsants & $\begin{array}{l}\text { carbamazepine, lamotrigine, } \\
\text { phenobarbital, phenytoin }\end{array}$ & expected $\downarrow$ ATV & Use with caution. \\
\hline Antidepressants & $\begin{array}{l}\text { tricyclic antidepressants } \\
\text { trazodone }\end{array}$ & $\begin{array}{l}\uparrow \text { tricylcic antidepressants } \\
\uparrow \text { trazodone }\end{array}$ & $\begin{array}{l}\text { Use with caution, TDM is recommended. } \\
\text { TDM is recommended and lower trazodone doses should } \\
\text { be used }\end{array}$ \\
\hline Antifungals & itraconazole, ketoconazole & $\begin{array}{l}\uparrow \text { itraconazole, } \\
\text { ketoconazole (ATV 400) }\end{array}$ & $\begin{array}{l}\text { If ATV is used with RTV, itraconazole or ketoconazole doses } \\
\text { of }>200 \mathrm{mg} / \text { day should be used with caution. }\end{array}$ \\
\hline Antihistamines & astemizole, terfenadine & no data available & $\begin{array}{l}\text { ATV/r should not be used in combination with drugs that } \\
\text { are substrates of the CYP3A4 and have narrow therapeutic } \\
\text { windows, such as terfenadine and astemizole. }\end{array}$ \\
\hline Antimicrobial agents & clarithromycin & $\begin{array}{l}\uparrow \text { clarithromycin } \\
\downarrow 14-O H \text {-clarithromycin } \\
\uparrow \text { ATV concentrations }\end{array}$ & $\begin{array}{l}\text { Dose reductions by } 50 \% \text { should be considered. } \\
\text { Combination with boosted ATV has not yet been studied. }\end{array}$ \\
\hline Antineoplastics & irinotecan & $\uparrow$ irinotecan & Contraindicated \\
\hline \multirow[t]{2}{*}{ Antimycobacterials } & rifabutin & $\uparrow$ rifabutin & $\begin{array}{l}\text { Reduce rifabutin dose to } 150 \mathrm{mg} \text { every other } \\
\text { day or } 3 \text { times/week. }\end{array}$ \\
\hline & rifampicin & severe $\downarrow$ ATV & Contraindicated. \\
\hline \multirow[t]{9}{*}{ Antiretroviral agents } & $\begin{array}{l}\text { NRTIs: } \\
\text { didanosine }\end{array}$ & $\downarrow$ ATV, $\downarrow$ didanosine & $\begin{array}{l}\text { Didanosine should be administered (with food) I h before or } \\
2 \mathrm{~h} \text { after ATV/r intake. }\end{array}$ \\
\hline & tenofovir & $\downarrow$ ATV, $\uparrow$ tenofovir & Avoid combination of tenofovir with $r$ unboosted ATV. \\
\hline & $\begin{array}{l}\text { NNRTIs: } \\
\text { efavirenz }\end{array}$ & $\downarrow$ ATV & $\begin{array}{l}\text { The recommended dose in treatment-naïve patients } \\
\text { is ATV/r } 300 / 100 \mathrm{mg} / \text { day. No recommendation has been } \\
\text { established in treatment-experienced patients. }\end{array}$ \\
\hline & nevirapine & expected $\downarrow$ ATV & Co-administration is not recommended. \\
\hline & etravirine & $\uparrow$ etravirine, $\downarrow$ ATV & ATV should be boosted with $r$. \\
\hline & $\begin{array}{l}\text { IPs: } \\
\text { indinavir }\end{array}$ & & $\begin{array}{l}\text { Contraindicated due to synergistic effect } \\
\text { on hyperbilirubinemia. }\end{array}$ \\
\hline & $\begin{array}{l}\text { saquinavir } \\
\text { (soft gelatin capsules) }\end{array}$ & $\uparrow$ saquinavir & $\begin{array}{l}\text { Appropiate recommendations for this combination have not } \\
\text { been established.TDM is recommended. }\end{array}$ \\
\hline & tipranavir & expected $\downarrow$ ATV & ATV and tipranavir should not be co-administered. \\
\hline & $\begin{array}{l}\text { INI: } \\
\text { raltegravir }\end{array}$ & $\uparrow$ raltegravir & $\begin{array}{l}\text { The clinical relevance of these data is unknown. } \\
\text { No changes in raltegravr dosign are recommended. }\end{array}$ \\
\hline Benzodiazepines & midazolam, triazolam & $\uparrow$ midazolam, triazolam & Contraindicated. \\
\hline \multirow[t]{2}{*}{$\begin{array}{l}\text { Calcium channel } \\
\text { blockers }\end{array}$} & diltiazem & $\begin{array}{l}\uparrow \text { diltiazem and } \\
\text { desacetyl-diltiazem }\end{array}$ & $\begin{array}{l}\text { Caution is warranted. } 50 \% \text { dose reduction of diltiazem } \\
\text { should be considered. }\end{array}$ \\
\hline & $\begin{array}{l}\text { felodipine, nifedipine, } \\
\text { nicardipine, verapamil }\end{array}$ & $\begin{array}{l}\uparrow \text { felodipine, nifedipine, } \\
\text { nicardipine, verapamil }\end{array}$ & $\begin{array}{l}\text { Caution is warranted and ECG monitoring is recommended. } \\
\text { Dose titration should be considered. }\end{array}$ \\
\hline Corticosteroids & fluticasone & $\uparrow$ fluticasone & Caution is warranted. \\
\hline Ergot derivatives & $\begin{array}{l}\text { dihydroergotamine, } \\
\text { ergotamine,ergonovine, } \\
\text { methylergonovine }\end{array}$ & $\uparrow$ ergot derivatives & Contraindicated. \\
\hline Gl motility agent & cisapride & 个cisapride & Contraindicated. \\
\hline $\begin{array}{l}\text { Acid suppressive } \\
\text { therapy }\end{array}$ & antiacids & $\downarrow$ ATV & $\begin{array}{l}\text { ATV should be adminsitered } 2 \mathrm{~h} \text { befote or } \mathrm{I} h \text { alter intake of } \\
\text { antiacids. }\end{array}$ \\
\hline
\end{tabular}

(Continued) 
Table 3 (Continued)

\begin{tabular}{|c|c|c|c|}
\hline Family & Drug & Effect on concentration & Recommendation \\
\hline & $\mathrm{H}_{2}$ receptor antagonists & $\downarrow$ ATV & $\begin{array}{l}\mathrm{H}_{2} \text { Receptor antagonist should not exceed a } 40 \mathrm{mg} \text { dose } \\
\text { equivalent of famotidine twice daily and ATV should be } \\
\text { administered with } r \text { simultaneously, with and/or at least } \\
10 \text { hours after the dose of the } \mathrm{H}_{2} \text {-receptor antagonist. }\end{array}$ \\
\hline & proton pump inhbitors & $\downarrow$ ATV & $\begin{array}{l}\text { ATV/r is recommended. Proton-pump inhibitor dose should } \\
\text { not exceed a } 20 \mathrm{mg} \text { dose/day, equivalent of omeprazole and } \\
\text { must be taken approximately I } 2 \text { hours prior to ATV/RTV in } \\
\text { antiretroviral-naïe patients. Proton-pump inhibitors should } \\
\text { not be used in treatment-experienced patients. }\end{array}$ \\
\hline Herbal products & St. John's wort & expected $\downarrow$ ATV & Contraindicated. \\
\hline $\begin{array}{l}\text { HMG-CoA reductase } \\
\text { Inhbitors }\end{array}$ & $\begin{array}{l}\text { lovastatin, simvastatin } \\
\text { atrovastatin, rosuvastatin }\end{array}$ & $\begin{array}{l}\uparrow \text { lovastatin, simvastatin } \\
\uparrow \text { atorvastatin, rosuvastatin }\end{array}$ & $\begin{array}{l}\text { Contraindicated. } \\
\text { Use the lowest possible dose of atorvastatin or rosuvastatin } \\
\text { with careful monitoring or consider other HMG-CoA } \\
\text { reductase inhibitor such as pravastatin or fluvastatin. }\end{array}$ \\
\hline Immuno-suppressants & $\begin{array}{l}\text { cyclosporine A, sirolimus, } \\
\text { tacrolimus }\end{array}$ & $\uparrow$ immunosuppressants & TDM is recommended. \\
\hline Neuroleptics & pimozide & $\uparrow$ pimozide & Contraindicated. \\
\hline Oral contraceptives & $\begin{array}{l}\text { ethinyl estradiol, } \\
\text { norethindrone }\end{array}$ & $\downarrow \uparrow$ oral contraceptives & $\begin{array}{l}\text { Due to possible alteration of oral contraceptives } \\
\text { concentrations, alternative/additional contraceptive measures } \\
\text { should be used when co-administered with ATV or ATV/r. }\end{array}$ \\
\hline PDE5 inhibitors & sildenafil, tadalafil, vardenafil & $\begin{array}{l}\uparrow \text { sildenafil, tadalafil, } \\
\text { vardenafil }\end{array}$ & $\begin{array}{l}\text { Do not exceed } 25 \mathrm{mg} \text { of sildenafil in } 48 \mathrm{~h}, 10 \mathrm{mg} \text { of taldalafil } \\
\text { in } 72 \text { hours or } 2.5 \mathrm{mg} \text { of vardenafil in } 72 \mathrm{~h} \text {. }\end{array}$ \\
\hline
\end{tabular}

Abbreviations: NRTI, nucleoside reverse transcriptase inhibitor; NNRTI, non-nucleoside reverse transcriptase inhibitor; PI, protease Inhibitor; INI, integrase Inhibitor; ATV, atazanavir; RTV, ritonavir;TDM, therapeutic drug monitoring; INR, international normalized ratio; ECG, electrocardiogram.

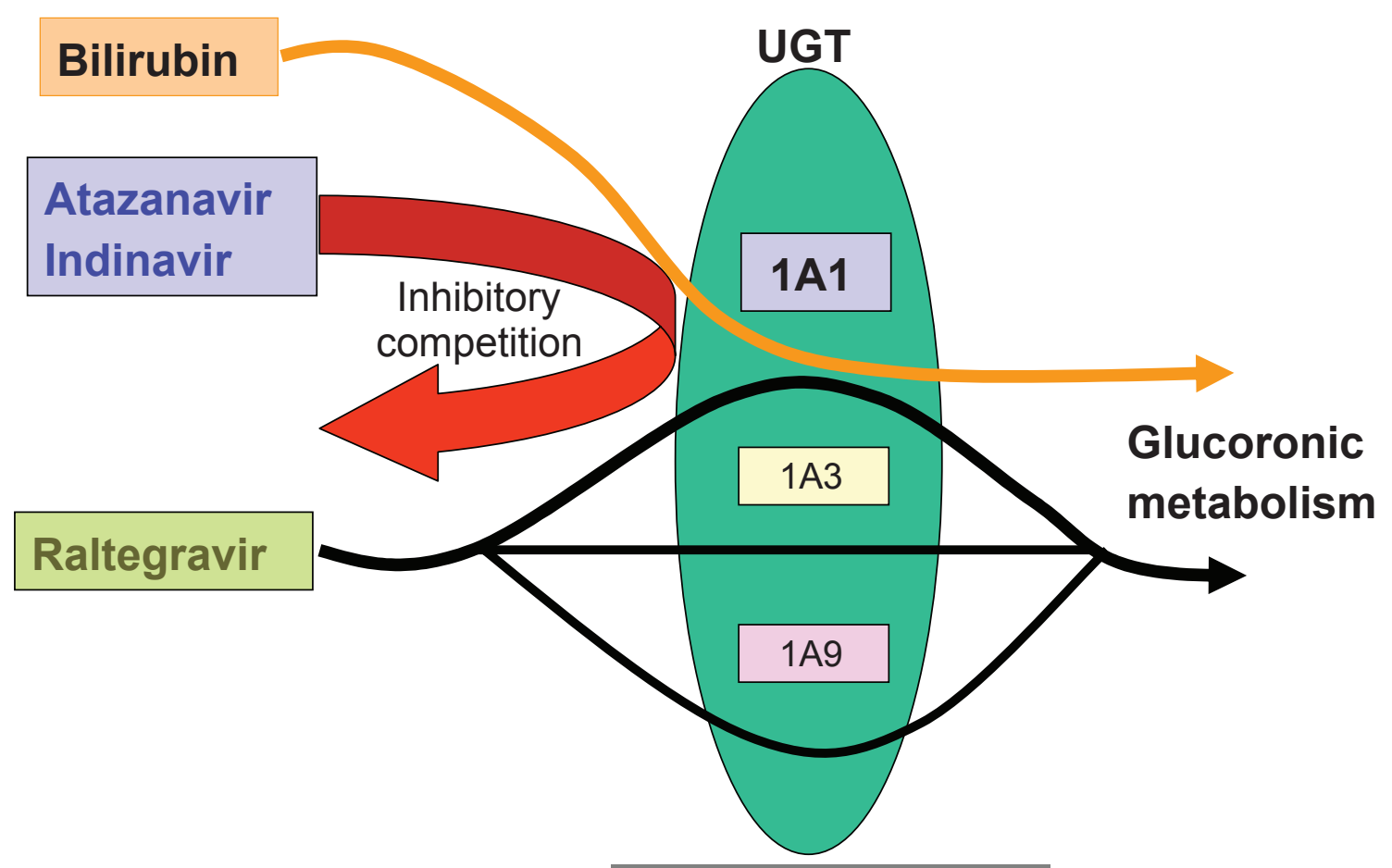

Gilbert: UGT $1 \mathrm{~A} 1{ }^{*} 28$

Figure 2 Antiretrovirals, bilirubin and UGT inhibition. 
constitutive CYP3A4 expression in the liver and gut when compared to subjects homozygous for the $2677 \mathrm{G}$ allele. ${ }^{39}$

Several polymorphisms at the UGT1A1 gene have been described. The wild type allele (UGT1A1*1) contains 6 TA repeats in the promoter (TA6) whereas the most common variant allele (UGTA1A1*28) contains 7 repeats (TA7) and is the main one responsible for the mild form of Gilbert's syndrome, an inherited unconjugated hyperbilirubinemia disorder. ${ }^{40-42}$ In a retrospective study conducted in 118 patients on a stable ATV/r regimen, the proportion of patients with grade 3-4 hyperbilirubinemia varied with distinct UGT1A1 genotypes: $80 \%$ for $7 / 7,29 \%$ for $6 / 7$ and $18 \%$ for $6 / 6$. In the multivariate analysis, having at least one TA7 allele at UGT1A1 significantly predicted grade 3-4 hyperbilirubinemia. ${ }^{30}$

Rotger et al quantified the relative contribution of the UGT1A $1 * 28$ allele and different antiretroviral combinations on the risk of hyperbilirubinemia in $96 \mathrm{HIV}$-infected patients. ATV bilirubin levels increased by $0.87 \mathrm{mg} / \mathrm{dL}$, while it was $0.46 \mathrm{mg} / \mathrm{dL}$ using indinavir. Patients homozygous for UGT1A1*28 had bilirubin levels increased by $0.3 \mathrm{mg} / \mathrm{dL}$. As a result, $67 \%$ of individuals homozygous for UGT1A1*28 and receiving either ATV or indinavir had hyperbilirubinemia in the jaundice range $(>2.5 \mathrm{mg} / \mathrm{dL})$, versus only $7 \%$ of those with the common allele not receiving any of these drugs. The implementation of UGT1A1*28 genotyping before initiation of antiretroviral therapy would lead to a theoretical $75 \%$ reduction in the number of patients experiencing jaundice. ${ }^{42}$

Other polymorphisms in the genes encoding for the UGT isoenzymes could also be associated with Gilbert's syndrome. ${ }^{40,41}$ Lankisch et al examined the effects of different polymorphisms in UGT1A1 (UGT1A1*28), UGT1A3 (-66) and UGT1A7 (-57T > G, W208R, N129K and R131K) genes on the risk of hyperbilirubinemia in patients treated with ATV. These isoenzymes are all inhibited by ATV. Interestingly, the homozygote haplotype for all 4 variants was present in up to $41 \%$ of patients with grade $3 / 4$ and in $100 \%$ of patients with grade 4 hyperbilirubinemia. Therefore, the combination in homozygosis at *28, UGT1A7-57G, UGT1A3-66C and UGT1A7 was identified as highly predictive of severe hyperbilirubinemia under ATV therapy. ${ }^{41}$

\section{Toxicity}

ATV is generally well tolerated, as shown by the fact that only $5 \%$ to $10 \%$ of patients discontinued the drug due to adverse events in the main registrational studies with 48 weeks of follow-up. Indirect (unconjugated) bilirubin elevation is the most frequent side effect reported with ATV therapy and is due to inhibition of the UGT, as mentioned above. This unconjugated bilirubin elevation is frequently seen within the first months on ATV therapy and tends to slightly decline thereafter due to metabolic compensation mechanisms. This laboratory abnormality only achieves clinical relevance (grade 3-4) in up to one third of patients across studies. Jaundice is infrequent $(<10 \%)$ and excessive bilirubin elevations leading to ATV discontinuation are rare (around $1 \%$ of treated patients). ${ }^{1}$ The risk for hyperbilirubinemia seems to be associated to ATV plasma levels, and is more frequent when high doses of ATV are given (ie, $600 \mathrm{mg}$ qd) or when ATV is boosted with r. ${ }^{9,25,29,30}$ Of note, hyperbilirubinemia is completely reversible after stopping ATV.

Grade 3-4 elevations in transaminases have been observed in $3 \%$ to $14 \%$ of patients receiving ATV. Liver enzyme elevations do not correlate with increased serum bilirubin and are more frequently seen in HIV subjects with underlying chronic hepatitis B or C. In the AI424-007 study, ${ }^{43}$ in which ATV was given in combination with didanosine and stavudine, grade 3-4 elevations in transaminases occurred in $20 \%$ of patients with chronic hepatitis B and in $40 \%$ of patients with chronic hepatitis $\mathrm{C}$, but in $<10 \%$ of HIV-monoinfected individuals. In studies AI424-00844 and AI424-034, ${ }^{5}$ ALT levels $>5$ times the upper limit of normality were seen respectively in $15 \%, 14 \%$ and $17 \%$ of seropositive patients for hepatitis B or C treated with ATV, efavirenz and nelfinavir. In study AI424-045, ${ }^{33} 20$ patients treated with $\mathrm{ATV} / \mathrm{r}$ and 18 with $\mathrm{LPV} / \mathrm{r}$, all seropositive for hepatitis B and/or C, experienced increases in ALT levels $>5$ times the upper limit of normality in $25 \%(5 / 20)$ and $6 \%$ (1/18) of cases, respectively. Therefore, liver function tests should periodically be monitored in patients on ATV with underlying chronic liver disease.

Patients on ATV may occasionally complain of gastrointestinal disturbances, although symptoms are generally mild. In the AI424-007 study, ${ }^{43}$ grade 3-4 nausea/vomiting, abdominal pain, or diarrhea occurred in only $2 \%$ to $3 \%$ of patients. Of note, these side effects do not seem to rise when ATV is boosted with r. Indeed, in the AI424-045, ${ }^{33}$ the incidence of grade 2-4 gastrointestinal symptoms was 3\% in the $\mathrm{ATV} / \mathrm{r}$ arm but was much higher in the LPV/r arm (11\%).

Some concern has been raised with respect to the potential cardiac toxicity of ATV, following sporadic reports in the literature. This adversity was not originally reported during the clinical development of the drug and has only rarely been noticed in the post-marketing period. ${ }^{45}$ ATV has been shown to prolong the PR interval in electrocardiograms performed on healthy volunteers as well as in HIV-infected patients. ${ }^{46}$ 
Abnormalities in atrioventricular conduction are generally asymptomatic, concentration-dependent and limited to first-degree atrioventricular block. Anecdotal reports of second-degree atrioventricular block and other conduction abnormalities have been published. ${ }^{1}$ A retrospective analysis of patients enrolled in the ATV expanded access program (AI424-900 study) has shown that QRS intervals increased by a median of $5 \mathrm{~ms}$ in 56 out of 75 (74.7\%) antiretroviralexperienced patients (66.7\% male), using either boosted or unboosted ATV. The PR and the QTc intervals did not change significantly. Interestingly, new asymptomatic bundle branch blocks were observed in 4 patients. ${ }^{47}$ According to pooled data from the manufacturer's prescribing information, the incidence of QTc interval prolongation in a total of 1793 patients treated with ATV was comparable to that of patients receiving other PIs, with none of the patients showing a QTc interval $>500 \mathrm{~ms} .{ }^{1}$ Since pre-existing cardiac conduction abnormalities was an exclusion criterion in many early ATV studies, the prevalence of electrocardiogram abnormalities in unselected populations remains unknown. An additive effect of ATV and drugs that prolong the PR interval (eg, beta-blockers, verapamil, digoxin) and the QT interval cannot be excluded; consequently, when possible these combinations should be avoided. Altogether, these observations show that periodic electrocardiogram monitoring is worthwhile in patients treated with ATV, particularly when boosted with $\mathrm{r}$.
Cases of nephrolithiasis in patients on ATV have been reported after marketing of ATV. ${ }^{48}$ This complication resembles the well known side effect of indinavir, which was able to produce kidney stones. In some instances, ATV crystals have been demonstrated in urine. However, this complication is very rare. In one retrospective study the prevalence of ATV-associated urolithiasis was $0.97 \% .{ }^{49}$ Patients with low water intake, high urinary $\mathrm{pH}$, and prior history of urinary stones are at higher risk for ATV-associated urine crystallization.

Unlike other PIs, ATV does not seem to negatively impact the lipid profile. ATV also seems to have less impact on insulin and overall on glucose metabolism than all other PIs. Following this observation a lack of involvement of the drug in morphological lipodystrophy abnormalities has been presumed, which is somewhat unique for PIs, although a longer follow-up is needed to confirm this singularity. ${ }^{50}$

\section{Clinical experience}

\section{Atazanavir in treatment-naïve subjects}

ATV has been compared with other potent agents such as nelfinavir, efavirenz, saquinavir and LPV/RTV as part of triple therapy with two nucleoside reverse transcriptase inhibitors (NRTI) in treatment-naïve patients (Table 4). Two studies, AI424-00743 and AI424-008, ${ }^{44}$ compared different doses of unboosted ATV with nelfinavir along with didanosine + stavudine or lamivudine + stavudine, respectively. The viro-

Table 4 Main randomized studies with atazanavir in antiretroviral-naïve patients

\begin{tabular}{|c|c|c|c|c|c|c|c|}
\hline Study & Phase & No & Backbone & Regimens & $\begin{array}{l}\text { Follow-up } \\
\text { (weeks) }\end{array}$ & $\begin{array}{l}\text { \% patients achieving } \\
\text { plasma HIV-RNA } \\
<\mathbf{4 0 0} \text { copies/mL (ITT) }\end{array}$ & $\begin{array}{l}\text { \% patients achieving } \\
\text { plasma HIV-RNA } \\
<\mathbf{5 0} \text { copies/mL (ITT) }\end{array}$ \\
\hline \multirow[t]{4}{*}{ Al424-007 43} & II & 420 & $\mathrm{~d} 4 \mathrm{~T}+\mathrm{ddl}$ & ATV $200 \mathrm{mg} q \mathrm{~d}$ & 48 & 61 & 28 \\
\hline & & & & ATV $400 \mathrm{mg}$ qd & & 64 & 36 \\
\hline & & & & ATV $500 \mathrm{mg}$ qd & & 59 & 42 \\
\hline & & & & NFV $750 \mathrm{mg}$ tid & & 56 & 39 \\
\hline \multirow[t]{3}{*}{ Al424-008 ${ }^{44}$} & $\mathrm{II} / \mathrm{III}$ & 467 & $\mathrm{~d} 4 \mathrm{~T}+3 \mathrm{TC}$ & ATV $400 \mathrm{mg}$ qd & 48 & 64 & 35 \\
\hline & & & & ATV $600 \mathrm{mg}$ qd & & 67 & 36 \\
\hline & & & & NFV I 250 mg bid & & 53 & 34 \\
\hline \multirow[t]{2}{*}{ Al424-034 } & III & 810 & $Z D V+3 T C$ & ATV $400 \mathrm{mg}$ qd & 48 & 70 & 32 \\
\hline & & & & EFV $600 \mathrm{mg}$ qd & & 64 & 37 \\
\hline \multirow[t]{2}{*}{ CASTLE $^{55}$} & III & 883 & TDF + FTC & ATV/RTV $300 / 100$ mg qd & 48 & 86 & 78 \\
\hline & & & & LPV/RTV 400/I00 mg bid & & 82 & 76 \\
\hline \multirow[t]{2}{*}{ Al424-08951 } & IV & 200 & $3 T C+d 4 T-X R$ & ATV $400 \mathrm{mg}$ qd & 96 & 85 & 70 \\
\hline & & & & ATV/RTV $300 / 100 \mathrm{mg}$ qd & & 86 & 75 \\
\hline \multirow[t]{2}{*}{ ALERT $^{54}$} & IV & 106 & TDF + FTC & ATV/RTV $300 / 100$ mg qd & 48 & 87 & 83 \\
\hline & & & & FPV/RTV I400/100 mg qd & & 79 & 75 \\
\hline
\end{tabular}

Abbreviations: ITT, intent-to-treat; VL, viral load; 3TC, lamivudine; d4T, stavudine; d4T-XR, extended-release stavudine; ddI, didanosine; TDF, tenofovir disoproxil fumarate; ATV, atazanavir; LPV, lopinavir/ritonavir; NFV, nelfinavir; FPV, fosamprenavir; RTV, ritonavir; EFV, efavirenz; ZDV, zidovudine; bid, twice daily; qd, once daily; tid, three times daily. 
logical response to both PIs was similar in terms of mean viral load reduction at 48 weeks and proportion of patients attaining undetectable viremia. Likewise, the increase in CD4 + T lymphocytes was similar for all groups in both studies. ATV and nelfinavir regimens were generally well tolerated, with the best efficacy/safety profile being found when ATV was given as $400 \mathrm{mg}$ qd. Indeed, this was the selected dose for later studies. The metabolic indulgence of ATV was one of the most striking findings of the AI424-007 and AI424-008 studies. Increases in total cholesterol at 48 weeks were $25 \%$ and $28 \%$ for nelfinavir in each trial, but only $5 \%$ and $7 \%$ for ATV (400 mg qd), respectively ( $p<0.05$ ). The same favorable behavior was seen for triglycerides $(1.5 \%$ and $7 \%$ increase in each study) over nelfinavir (42\% and $50 \%$ increase in each study).

The AI424-034 study ${ }^{5}$ compared unboosted ATV with efavirenz (one if not the most preferred third agent in drugnaïve patients) in combination with zidovudine + lamivudine as the nucleoside backbone. Despite the recruitment of many patients with high viral loads ( $42 \%$ with $\geq 5 \log$ HIV-RNA copies $/ \mathrm{mL}$ ) and low CD4 counts (median of 282 cells $/ \mu \mathrm{L}$ ), the performance was excellent and comparable after 48 weeks: $70 \%$ and $64 \%$ of patients with ATV and efavirenz, respectively, attained $<400$ HIV-RNA copies/mL. Some technical problems in the processing of specimens led to low rates of patients with values $<50$ copies $/ \mathrm{mL}$ in both groups $(32 \%$ with ATV and 37\% with EFV). The regimens were comparable with respect to the magnitude and rate of CD4 + T cell gains. Interestingly, ATV treatment was associated with a more favorable lipid profile than was efavirenz treatment. In fact, the mean increase in total and low-density lipoprotein (LDL) cholesterol was significantly higher for efavirenz than for ATV $(+21 \%$ and $+18 \%$ versus $+2 \%$ and $+1 \%$, respectively). The high-density lipoprotein (HDL) cholesterol fraction rose in both groups, but was more pronounced with efavirenz than with ATV $(+24 \%$ versus $+13 \% ; \mathrm{p}<0.001)$. Finally, mean triglyceride levels decreased with ATV $(-9 \%)$ and increased with efavirenz $(+23 \%)(\mathrm{p}<0.001)$. No significant variations in glucose metabolism were noticed in either group, although patients on efavirenz tended to show slight increases in fasting insulin concentrations.

These initial registrational trials did not compare boosted ATV with other PIs or non-nucleoside reverse transcriptase inhibitors (NNRTI), and boosted ATV was initially disregarded for use in drug-naïve patients, at least in North America. These trials were followed by the AI424-089 study, a randomized, multicenter, 96-week study designed to compare the efficacy and safety of ATV/r to ATV, each given once daily in combination with once-daily lamivudine and extended-release stavudine in drug-naïve patients. ${ }^{51}$ In this comparison of boosted and unboosted ATV, the overall efficacy results were comparable. However, while not statistically significant, the rates of response were higher and emergence of PI resistance lower in subjects on ATV/r than in those on unboosted ATV. Based on these results, other studies using boosted ATV in treatment-naïve subjects were designed. The concern about a lower potency of unboosted ATV has been recorded in several antiretroviral treatment guidelines, in which ATV alone is only described as an alternative (but not preferred) PI in drug-naïve patients. ${ }^{24}$ Unboosted ATV may be chosen in highly selected circumstances as initial therapy for patients when a once-daily regimen without $\mathrm{r}$ is desired, in subjects not candidates for NNRTI-based regimens, and in patients with underlying cardiovascular risk factors in whom hyperlipidemia may be particularly undesirable..$^{52}$ Of course, TDM would be desirable in these circumstances.

A recent prospective randomized phase IV study has explored the efficacy of the combination of unboosted ATV plus enteric-coated didanosine (ddI) and emtricitabine (FTC) in comparison with efavirenz and ZDV/3TC or TDF/FTC in 1045 patients, mainly from resource-limited countries (ACTG A5175). The rationale for the use of a ddI/FTC/ATV regimen is obvious, since this once-daily combination might be relatively inexpensive, not require refrigeration of any compound (one of the main drawbacks when $r$ has to be used), and be relatively cheaper. Unfortunately, after a planned interim review, the study found a significantly greater risk of treatment failure with $\mathrm{ddI}+\mathrm{FTC}+\mathrm{ATV}$ compared with ZDV + 3TC + EFV. ${ }^{53}$

Finally, ATV/r has been compared with two of the preferred boosted PI regimens in treatment-naïve patients: fosamprenavir (FPV)/r and LPV/r. The ALERT study was a relatively small randomized study comparing FPV/r versus ATV/r both long with TDF/FTC. ${ }^{54}$ The study included 106 participants, 53 in each arm. It should be noted that FPV (1400 mg) was used once a day with only $100 \mathrm{mg}$ of $r$ instead of the usual twice-daily regimen using $200 \mathrm{mg}$ of r. Both regimens performed similarly well with respect to virologic suppression and CD4 count gains. At week 48, intent-to-treat analysis showed similar responses to $\mathrm{FPV} / \mathrm{r}$ and ATV/r, being plasma HIV-RNA $<50$ copies $/ \mathrm{mL}$ in $75 \%$ $(40 / 53)$ and $83 \%(44 / 53)$ of patients, respectively. Fasting total LDL/HDL cholesterol changes from baseline were also similar, although week 48 median fasting triglycerides were higher with FPV/r than with ATV/r (150 versus $131 \mathrm{mg} / \mathrm{dL}$, respectively). FPV/r-treated patients experienced fewer 
treatment-associated grade $2-4$ adverse events (15\% versus $57 \%$ ), with differences mainly driven by ATV-associated hyperbilirubinemia.

The most relevant trial using ATV/r in treatmentnaïve patients conducted so far is the CASTLE study. ${ }^{55}$ In this open-label, international, non-inferiority study, 883 antiretroviral-naïve patients were randomly assigned to receive ATV/r 300/100 mg qd or LPV/r 400/100 mg twice daily, in combination with a fixed-dose of TDF/FTC. At 48 weeks, plasma HIV-RNA $<50$ copies/mL were seen at similar rates in both arms (78\% and 76\%, respectively) and CD4 gains were also comparable. Serious adverse events occurred in $12 \%$ of patients in the ATV/r group and in $10 \%$ of patients in the LPV/r group. However, a better lipid profile was observed in patients taking ATV/r compared to those taking LPV/r. Moreover, gastrointestinal side effects were more common in the LPV/r group, while those receiving ATV/r were more likely to experience jaundice. Both treatments, however, were very well tolerated overall. It should be noted that CASTLE was an open-label study and 3 capsules twice daily of LPV/r instead of the current 2 tablets bid were used.

Altogether, these studies support the use of once-daily $\mathrm{ATV} / \mathrm{r}$ as a good first-line treatment option in drug-naïve patients. Studies comparing the effectiveness of ATV/r and efavirenz (ACTG A5202) or nevirapine (ARTEN and NEwArT studies) as first-line therapy are ongoing.

\section{Atazanavir in treatment-experienced failing patients}

It must be acknowledged that the approval of ATV was accelerated based on the results of another three clinical trials run in patients with virological failure under PI-containing regimens (Table 5). In this adverse setting, the AI424-009 study ${ }^{56}$ compared two rescue regimens based on ATV (400 and $600 \mathrm{mg}$ ) plus SQV (1200 mg) once a day versus SQV/r (400/400 mg) twice daily either in combination with two NRTI chosen based on phenotypic susceptibility data. The rationale for using ATV + SQV was based on the evidence of a booster effect of the former on SQV by inhibiting the cytochrome P450 3A4 isoenzyme in the liver. ${ }^{57}$ More than $85 \%$ of patients had prior PI experience and the median duration of prior PI therapy was approximately 2 years. The best virological response at 48 weeks was found in the ATV $400 \mathrm{mg}$ qd group (41\%) over the ATV $600 \mathrm{mg}$ qd (29\%) or SQV/r groups (35\%). There were fewer adverse event discontinuations in the ATV/r groups ( $9 \%$ and $11 \%$, respectively) than in the SQV/r arm $(30 \%)$. Moreover, none of the ATV groups showed the adverse effects on lipids seen in the SQV/r arm.

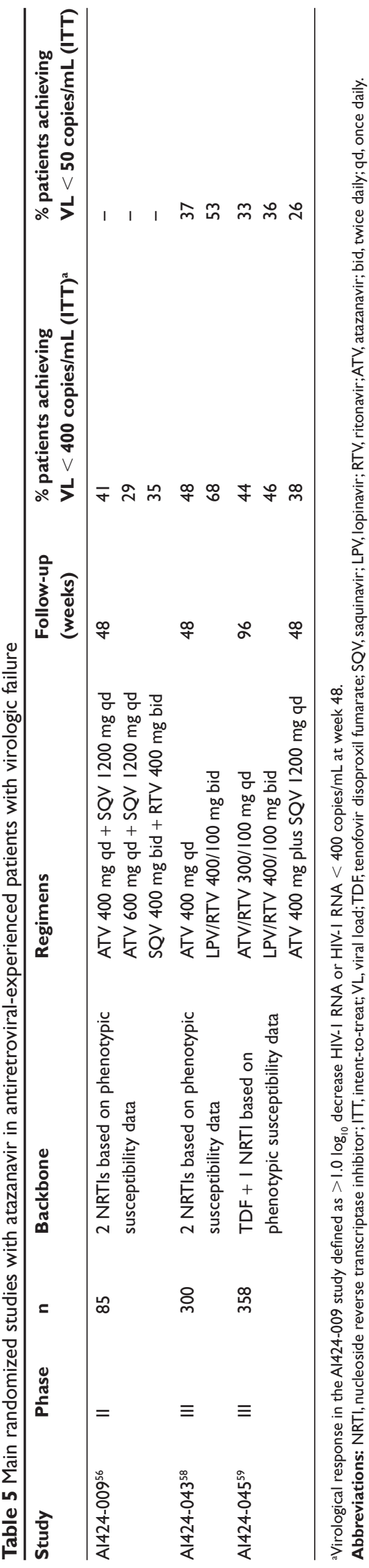

Therapeutics and Clinical Risk Management 2009:5 
In the AI424-043 study ${ }^{58}$ all patients had failed with at least one PI and were rescued with unboosted ATV versus LPV/r along with a nucleoside backbone selected according to resistance testing. LPV/RTV resulted in a significantly greater reduction in plasma HIV-RNA than unboosted ATV $\left(-2.02\right.$ versus $-1.59 \log _{10}$ copies $\left./ \mathrm{mL}, \mathrm{p}<0.001\right)$ at week 48 . Moreover, CD4 gains were higher with LPV/r than with ATV (169 versus 112 cells $/ \mu \mathrm{L}$ ). However, in the subset of patients with lack of NRTI resistance mutations at baseline, both regimens demonstrated comparable virologic suppression. The metabolic indulgence of ATV was especially manifest in this study. While LPV/r increased lipid levels and induced insulin resistance, these parameters remained stable in the ATV arm.

The third study (AI424-045) compared boosted ATV with $\mathrm{LPV} / \mathrm{r} .{ }^{59}$ The trial expected to find comparable efficacy and less toxicity with ATV/r. Patients who had failed two or more HAART regimens were randomized to ATV/r (300/100 mg qd), ATV/SQV (400/1200 mg qd) or LPV/r (400/100 mg bid), all along with TDF once daily and another NRTI. Approximately $40 \%$ of patients harbored $\geq 4$ NRTI resistance mutations and more than one third harbored $\geq 4$ PI resistance mutations. The virologic and immunologic results were worse for patients treated with ATV/SQV as compared with the other two groups (LPV/r and ATV/r), and therefore this arm was stopped at 24 weeks. In the intention-to-treat analysis at 96 weeks, similar virological efficacy was demonstrated for the remaining ATV/r and $\mathrm{LPV} / \mathrm{r}$ arms, with $44 \%$ versus $46 \%$ of patients achieving $<400$ HIV-RNA copies/mL, respectively. CD4 gains at that time were also comparable $(+160$ and +142 cells $/ \mu \mathrm{L}$, respectively). ${ }^{33}$ Although response rates were similar when fewer than 4 PI-resistance associated mutations were present at baseline, $\mathrm{LPV} / \mathrm{r}$ was superior to $\mathrm{ATV} / \mathrm{r}$ in patients with more PI resistance mutations. This result suggested that ATV/r is of similar efficacy to LPV/r in antiretroviral-experienced patients with a limited extent of PI resistance, but it was inferior when a greater PI resistance was present. The tolerability of the three regimens was good and comparable, although only the ATV-containing groups benefited from less frequent gastrointestinal disturbances and significant reductions in total cholesterol, LDL cholesterol, and triglyceride concentrations. Moreover, in contrast with LPV/r, patients on ATV/r showed a significantly lower use of anti-diarrheal and lipid-lowering agents. The only drawback was grade 3-4 hyperbilirubinemia, which developed in $53 \%$ on ATV/r, a rate greater than expected and for which there is no clear explanation so far.
Despite the good performance of boosted ATV-based regimens in short- and long-term treatment of antiretroviralexperienced patients, its efficacy may be impaired in heavily pretreated patients. In terms of virological potency, many studies have concluded that as salvage therapy in antiretroviral-experienced patients, ATV/r could be a valuable option, unless a high number of PI resistance mutations are present. ${ }^{60,61}$ Moving a further step, the results of the French prospective NADIS cohort have concluded that $\mathrm{ATV} / \mathrm{r}$-containing regimens may be useful in heavily antiretroviral-experienced patients as long as failure has not occurred on LPV/r. ${ }^{11}$

Studies comparing the antiretroviral efficacy, safety and effect of serum lipids of ATV/r versus LPV/r in HIV subjects who have experienced their first virologic failure while receiving a NNRTI-containing HAART regimen are currently ongoing (eg, AI424-103 trial).

Finally, boosted double PI regimens (r plus 2 additional PIs) gained interest a few years ago as a treatment option for multiple treatment-experienced patients with little or no options. The advent of new antiretrovirals, such as enfuvirtide, raltegravir, darunavir, maraviroc and etravirine, with the ability to achieve long-term viral load reductions in heavily antiretroviral-experienced patients with relatively few, manageable toxicities, and low drug interactions has clearly halted the research on double boosted PIs.

\section{Atazanavir in switch studies}

The long-term adverse effects and the difficulty of continuous almost perfect adherence to antiretroviral regimens have led to assessment of the impact of strategies aimed to simplify therapy. Obviously, a requirement is preservation of viral suppression and reduced risk of toxicities. As a simplification strategy, ATV-based regimens may offer several therapeutic advantages, including a convenient once-daily dosing schedule, low pill burden and lack of metabolic undesirable side effects compared to efavirenz or other PI-based regimens (Table 6).

In the AI424-044 study, ${ }^{62}$ patients completing $\geq 48$ weeks in another trial (AI424-008) with a plasma HIV-RNA $<10,000$ copies $/ \mathrm{mL}$ were randomized to continue on ATV (400 or $600 \mathrm{mg} \mathrm{qd}$ ) or switch from nelfinavir to ATV (400 mg qd). After 24 weeks of ATV therapy, $83 \%, 85 \%$ and $87 \%$ of subjects in the ATV $400 \mathrm{mg}$, ATV $600 \mathrm{mg}$ and switch groups, respectively, had plasma HIV-RNA $<400$ copies $/ \mathrm{mL}$. These figures were $76 \%, 76 \%$ and $63 \%$, respectively, at week 48 in the prior AI424-008 study. Patients switched from nelfinavir to ATV showed significant mean declines in total cholesterol 
Table 6 Main switch studies with atazanavir

\begin{tabular}{|c|c|c|c|c|c|c|c|}
\hline Study & Phase & $\mathbf{n}$ & Backbone & $\begin{array}{l}\text { Previous } \\
\text { regimen }\end{array}$ & Intervention & $\begin{array}{l}\text { Follow-up } \\
\text { (weeks) }\end{array}$ & Main conclusion \\
\hline Al424-04462 & III & 346 & $\mathrm{~d} 4 \mathrm{~T}+3 \mathrm{TC}$ & $\begin{array}{l}\text { ATV } 400 \mathrm{mg} \text { qd } \\
\text { ATV } 600 \mathrm{mg} \text { qd } \\
\text { NFV } 1250 \mathrm{mg} \text { bid }\end{array}$ & $\begin{array}{l}\text { Continue on ATV ( } 400 \text { or } \\
600 \mathrm{mg} \text { ) or switch from } \\
\text { NFV to ATV } 400 \mathrm{mg} \text { qd }\end{array}$ & 24 & $\begin{array}{l}\text { Maintenance of virologic suppression } \\
\text { and significant improvement in lipid } \\
\text { profile in patients switched to ATV }\end{array}$ \\
\hline Al424-067 68 & III & 246 & $2 \mathrm{NRTI}$ & $\begin{array}{l}\text { PI with or } \\
\text { without RTV }\end{array}$ & $\begin{array}{l}\text { Immediate switch to ATV } \\
400 \text { mg qd or delayed } \\
\text { switch after } 24 \text { weeks }\end{array}$ & 48 & $\begin{array}{l}\text { Virologic rebounds }>50 \text { copies } / \mathrm{mL} \text {, } \\
15 \% \text { in immediate switch and } 10 \% \text { in } \\
\text { delayed switch group. Improvement } \\
\text { in lipid profile in hyperlipidemic } \\
\text { patients }\end{array}$ \\
\hline Al424-09765 & III & 419 & 2 NRTI & $\begin{array}{l}\text { PI with or } \\
\text { without RTV }\end{array}$ & $\begin{array}{l}\text { Continue existing Pl or } \\
\text { switch to ATV ( } 400 \mathrm{mg} \text { qd) or } \\
\text { to ATV/RTV ( } 300 / 100 \mathrm{mg} \text { qd) } \\
\text { if receiving TDF }\end{array}$ & 48 & $\begin{array}{l}\text { Maintenance of virologic suppression } \\
\text { and improvement in lipid profile in } \\
\text { patients switched to ATV }\end{array}$ \\
\hline SLOAT ${ }^{66}$ & IV & 189 & $2 \mathrm{NRTI}$ & LPV/RTV & $\begin{array}{l}\text { Continue on LPV/RTV or } \\
\text { switch to ATV ( } 400 \mathrm{mg} \text { qd) or } \\
\text { to ATV/RTV ( } 300 / 100 \mathrm{mg} \text { qd) } \\
\text { if receiving TDF }\end{array}$ & 24 & $\begin{array}{l}\text { Maintenance of virologic suppression } \\
\text { and improvement in lipid profile in } \\
\text { patients switched to ATV }\end{array}$ \\
\hline ATAZIP ${ }^{67}$ & IV & 265 & $2 \mathrm{NRTI}$ & LPV/RTV & $\begin{array}{l}\text { Continue on LPV/RTV or } \\
\text { switch to ATV ATV/RTV } \\
(300 / 100 \mathrm{mg} \text { qd) }\end{array}$ & 48 & $\begin{array}{l}\text { Maintenance of virologic suppression } \\
\text { and improvement in lipid profile in } \\
\text { patients switched to ATV }\end{array}$ \\
\hline $\operatorname{ReAL}^{73}$ & IV & 200 & 2 NRTI & $\begin{array}{l}\text { PI/ritonavir } \\
\text { (72\% LPV/RTV) }\end{array}$ & $\begin{array}{l}\text { Continue existing PI or } \\
\text { switch to ATV/RTV } \\
\text { (300/I00 mg qd) in } \\
\text { patients with } \\
\text { lipohypertrophy }\end{array}$ & 48 & $\begin{array}{l}\text { Maintenance of virologic suppression } \\
\text { and improvement in lipid profile but } \\
\text { no significant change in body compo- } \\
\text { sition in patients switched to ATV }\end{array}$ \\
\hline
\end{tabular}

Abbreviations: NRTI, nucleoside reverse transcriptase inhibitor; PI, protease inhibitor; ITT, intent-to-treat; VL, viral load; 3TC, lamivudine; d4T, stavudine; LPV, lopinavir; NFV, nelfinavir; RTV, ritonavir;ATV, atazanavir; bid, twice daily; qd, once daily.

$(-16 \%)$, fasting LDL cholesterol (-21\%), and fasting triglycerides $(-28 \%)(p<0.0001)$ by week 12 of ATV therapy, approaching baseline values.

Further studies have confirmed the benign lipid profile of ATV. The AI424-067 study ${ }^{63}$ was designed as a switch trial with the aim of managing hyperlipidemia in patients with well-controlled HIV replication. Preliminary 12-week data were reported a few years ago from 246 participants on stable HAART with undetectable viral load and elevated LDL cholesterol. They were randomly assigned to either continue their current PI-based regimen or switch to unboosted ATV while remaining on the same NRTIs. After 12 weeks, patients in the ATV arm maintained virological suppression while experiencing a $35 \%$ decrease in triglycerides, a $15 \%$ reduction in LDL cholesterol, an 18\% drop in total cholesterol, and $14 \%$ increase in HDL cholesterol. In addition, the study comprised an immediate switch group in which the PI was replaced by ATV $400 \mathrm{mg}$ qd and a delayed switch group in which subjects continued to receive their prior PI-containing regimen for the first 24 weeks and then switched to ATV $400 \mathrm{mg}$ qd. The results at 48 weeks confirmed that the switch from any PI (r-boosted or not) to ATV $400 \mathrm{mg}$ qd resulted in clinically relevant reductions in fasting LDL cholesterol. However, rates of viral rebound were $15 \%$ and $10 \%$ in the immediate and delayed switch groups, respectively. It should be noted that most of these patients had been exposed to suboptimal dual NRTI therapy in the past, and in this situation boosted instead of unboosted ATV would have been preferred by most clinicians to ensure enough drug exposure. ${ }^{64}$

The Switch to Another Protease Inhibitor Study (SWAN or AI424-097 study) ${ }^{65}$ was a 48-week, open-label, prospective trial involving HIV patients with virologic suppression who were receiving stable PI-based regimens (with or without r). Patients were randomized 2:1 to switch to ATV ( $400 \mathrm{mg} /$ day) or, if they were receiving TDF, to ATV/r (300/100 mg qd) or to continue on their prior PI. After 48 weeks, patients who switched to ATV showed significantly fewer total cholesterol, fasting triglyceride, and non-HDL cholesterol 
elevations than did patients in the comparator PI group $(p<0.001)$. For patients with prior exposure to boosted PI regimens, the 2 treatment groups had comparable rates of virologic rebound ( $8 \%$ for the ATV group versus $11 \%$ for the comparator PI group). In contrast, significantly lower rebound rates were recognized for ATV versus comparator PI groups in the subset of patients with prior exposure to unboosted PIs ( $5 \%$ versus $22 \%$; $p<0.001)$. A limitation of the study was that nearly half of the study participants entered the trial taking an obsolete unboosted PI modality and almost everyone switched to ATV did not take r, which is not the current standard of care.

The AI424-100 study tried to compare the change from baseline in fasting non-HDL cholesterol between hyperlipidemic subjects who were switched to an ATV/RTV-regimen and those who continued on a LPV/r regimen. Unfortunately, the study was prematurely discontinued due to poor enrolment and no efficacy analyses were performed. This issue was finally addressed by two Spanish phase IV studies, the SLOAT and the ATAZIP trials.

In the Simplification Lopinavir to Atazanavir (SLOAT) study, ${ }^{66}$ patients receiving LPV/r-based regimens (with or without hyperlipidemia) and having undetectable plasma HIV-RNA for longer than 24 weeks were randomized to continue on the same therapy or switch to ATV (400 mg qd) or to ATV/r (300/100 mg qd) if receiving TDF. The rate of virological failures at 48 weeks did not differ between groups. A significant reduction $(\mathrm{p}<0.001)$ was seen in median total cholesterol $(-19 \mathrm{mg} / \mathrm{dL})$ and triglycerides $(-80 \mathrm{mg} / \mathrm{dL})$ in the ATV switch group, whereas no significant changes occurred in the control LPV/r arm. Greater reductions in total cholesterol and triglycerides were seen in patients switched to ATV without $r$ boosting.

The ATAZIP study ${ }^{67}$ evaluated 248 individuals on stable LPV/RTV-based therapy (plasma HIV-RNA $<200$ copies/mL for longer than 6 months) who were randomized to either continue on the capsule formulation of LPV/r twice daily or switch to ATV/r (300/100 mg) qd. All individuals with more than $4 \mathrm{PI}$-associated resistance mutations and/or who had failed more than $2 \mathrm{PI}$-containing regimens were excluded from the study. Although HDL cholesterol did not change in either group, significantly more favorable shifts in total cholesterol, LDL cholesterol and triglycerides were observed in the ATV/r arm in comparison to the LPV/r arm. Virologic failure was uncommon and occurred in only $5 \%$ of ATV $/ \mathrm{r}$ recipients and $6 \%$ of LPV/r patients. Virologic failure was typically associated with a prior history of PI failure and/or presence of baseline major PI resistance mutations.
In addition to a better lipid profile, several studies have attempted to evaluate the effects on glucose tolerance following switch to ATV from PI-based regimens. The rationale was derived from prior information showing that ATV seems to have less effect on glucose metabolism than other PIs. ${ }^{68}$ In a study which included 21 highly pretreated HIV-infected subjects with metabolic alterations, the switch to an unboosted ATV-containing regimen revealed a significant improvement in glucose tolerance ${ }^{69}$ Likewise, in 9 HIV-infected men with dyslipidemia under a stable PI-containing regimen, the switch to ATV/RTV improved significantly insulin resistance, measured by the gold-standard euglycemic clamp method. ${ }^{70}$

ATV is less likely to induce lipodystrophy than other PIs. Based on data at week 48 from a substudy of the AI424-034 trial, ${ }^{5}$ it would appear that ATV has little effect on changes in fat redistribution. ${ }^{71}$ This substudy focused on subjects with CD4 counts $>100$ cells $/ \mu \mathrm{L}$, whose initial antiretroviral therapy consisted of ZDV + 3TC plus either EFV or ATV. There was no evidence of lipoatrophy at 48 weeks in any treatment arm; although there was a small increase in both abdominal subcutaneous and limb fat levels, which was not statistically significant. Moreover, there was an increase in the visceral fat by computed tomography with either drug combination. This study could be criticized in that the 48-week follow-up might be insufficient to detect subtle or delayed deleterious effects. However, in the AI424-007 trial, lipodystrophy continued to be infrequent and not significant compared to nelfinavir after 48 weeks on unboosted ATV.43

It is still unclear whether a switch from other PIs to ATV could ameliorate or even improve lipodystrophic effects of prior antiretroviral regimens. In a case series, 3 patients experienced a regression of dorso-cervical and abdominal fat accumulation after switching the existing PI to ATV. ${ }^{72}$ However, switching from PIs to ATV/r did not significantly reduce visceral fat accumulation in the abdomen at 48 weeks in the ReAL study. ${ }^{73}$ This trial evaluated the impact on body composition of switching from any twice-daily r-boosted PI to a once-daily ATV/r regimen in patients with lipohypertrophy (fat accumulation). Participants had been taking a boosted PI for a median of 24 months (LPV/r in 72\%). No significant differences in visceral fat were seen comparing the two groups after 1 year, suggesting no meaningful effect of treatment switch on the primary study outcome. However, patients who switched to ATV experienced a significant reduction in all fasting lipids, while antiviral efficacy was preserved. This study is still ongoing and results at week 96 will soon be available. Nevertheless, lipid improvements seen with ATV most likely will not translate into significant body 
fat changes within 2 years, since fat abnormalities generally take longer to recover. Long-term studies will be needed to assess the true effect of ATV on lipodystrophy.

Although ATV has proved to be a more metabolic-friendly drug that other antiretrovirals, and may help to manage metabolic side effects, it remains unclear weather switching to ATV may be a better approach than adding lipid-lowering medications to prior medications. However, any improvement in the lipid profile on ATV is likely to be beneficial in terms of reducing cardiovascular risk, and may decrease the required dose of lipid-lowering medications. A recent retrospective study has shown that a switch to ATV in HIV-infected antiretroviral-experienced patients caused significant reductions in plasma lipids and a modest but significant reduction in the normalized-for-age cardiovascular risk score, mainly in patients with higher baseline total cholesterol and triglycerides. ${ }^{74}$ Nevertheless, another study revealed that the switch from PIs to ATV in antiretroviral-experienced patients did not result in recognizable improvements in endothelial function despite benefits in the serum lipids. ${ }^{75}$

\section{Atazanavir/ritonavir monotherapy}

In an attempt to simplify antiretroviral regimens as much as possible, recent reports have claimed that $\mathrm{PI} / \mathrm{r}$ monotherapy could be an alternative option in some patients, especially as a maintenance strategy once virological control has been achieved. The proof-of concept studies for this strategy were originally conducted with LPV/r, ${ }^{76,77}$ following which 3 uncontrolled studies with ATV/RTV monotherapy have been performed, resulting in conflicting results.

ATV/r was tested in a prospective pilot study of $34 \mathrm{HIV}$ adults with virological suppression for $\geq 48$ weeks receiving their first PI regimen. ${ }^{78}$ All participants switched to ATV/r at entry and discontinued the NRTI backbone after 6 weeks. Three participants $(9 \%)$ experienced virologic failure at weeks 12, 14 and 20 after simplification, with plasma HIV-RNA levels of 4730, 1285 and 28397 copies $/ \mathrm{mL}$, respectively. Intriguingly, resistance testing at failure did not identify any PI resistance mutation. Plasma ATV concentrations at failure were low or below detection in 2 out of 3 subjects. The authors concluded that ATV/r maintenance monotherapy could be a valuable option in a subset of HIV patients. However, predicting those who would fail was unclear.

In another pilot trial using ATV/r as maintenance therapy, premature discontinuation was recommended when 15 of the planned 30 patients had been recruited, because 5 cases of virological failure were documented. In failing patients, viral rebound occurred between weeks 12 and 16. Plasma ATV concentrations did not predict the outcome. Again, no PI resistance mutations were found in failing patients. ${ }^{79}$ The investigators concluded that $\mathrm{ATV} / \mathrm{r}$ as maintenance monotherapy in HIV-1 infection should not be considered as potent as conventional triple antiretroviral therapy.

The third study, named ATARITMO, tried to determine the feasibility of ATV/r maintenance monotherapy along with its effects on viral replication in compartments other than plasma, such as the CSF and seminal plasma. At week 24, 3/20 patients had detectable viremia (HIV-RNA > 100 copies/mL) in CSF and 2/15 in semen, despite viral suppression in plasma ( $<50$ HIV-RNA copies/mL). Interestingly, samples with elevated HIV-RNA ( $>500$ copies/mL) in CSF were all wild type in $\mathrm{CSF}^{80}$ Altogether, the general view is that ATV/r monotherapy, as with other PIs, must not be considered as an acceptable optional strategy when any modality of triple antiretroviral regimens can be afforded. ${ }^{81}$

\section{Conclusion}

ATV has opened a new PI era with safer and more convenient compounds. While it retains the potency of the oldest robust PIs, it offers the advantage of simplicity and minimal toxicity both in treatment-naïve and in treatment-experienced patients. Once the possibility of controlling HIV infection has already been achieved by choosing combinations of the 25 drugs currently available within the HIV treatment armamentarium, the availability of this kind of friendly drug may enable an improvement in the quality of life, a variable of growing relevance as the life expectancy of HIV-infected persons is approaching that of uninfected individuals.

\section{Acknowledgments}

This work was funded in part by grants from Fundación Investigación y Educación en SIDA (IES), the European NEAT consortium, Agencia Lain Entralgo, and Red de Investigación en SIDA (RIS, ISCIII-RETIC RD06).

\section{Disclosures}

All authors acknowledge no conflicts of interests with this work.

\section{References}

1. Bristol Myers Squibb Company. Princeton, NJ 08543, USA. Reyataz product information. [Accessed 31 Aug 2008]. Available from: http:// packageinserts.bms.com/pi/pi_reyataz.pdf

2. Colonno R, Thiry A, Limoli K, Parkin N. Activities of atazanavir (BMS-232632) against a large panel of HIV type 1 clinical isolates resistant to one or more approved protease inhibitors. Antimicrob Agents Chemother. 2003;47(4):1324-1333. 
3. Drusano G, Bilello J, Preston S, et al. Hollow-fiber unit evaluation of a new HIV type 1 protease inhibitor, BMS-232632, for determination of the linked pharmacodynamic variable. J Infect Dis. 2001;183(7):1126-1129.

4. Colonno R, Rose R, McLaren C, Thiry A, Parkin N, Friborg J. Identification of $150 \mathrm{~L}$ as the signature atazanavir (ATV)-resistance mutation in treatment-naive HIV-1-infected patients receiving ATV-containing regimens. J Infect Dis. 2004;189(10):1802-1810.

5. Squires K, Lazzarin A, Gatell JM, et al. Comparison of once-daily atazanavir with efavirenz, each in combination with fixed-dose ZDV and lamivudine, as initial therapy for patients infected with HIV. J Acquir Immune Defic Syndr. 2004;36(5):1011-1019.

6. Sista P, Wasikowski B, Lecocq P, Pattery T, Bacheler L. The HIV-1 protease resistance mutation $\mathrm{I} 50 \mathrm{~L}$ is associated with resistance to atazanavir and susceptibility to other protease inhibitors in multiple mutational contexts. J Clin Virol. 2008;42(4):405-408.

7. De Mendoza C, Garrido C, Corral A, et al. Changing rates and patterns of drug resistance mutations in antiretroviral-experienced HIV-infected patients. AIDS Res Hum Retroviruses. 2007;23(7):879-885.

8. Johnson V, Brun-Vezinet F, Clotet B, et al. Update of the drug resistance mutations in HIV-1: Spring 2008. Top HIV Med. 2008;16(1):62-68.

9. Barrios A, Rendon AL, Gallego O, et al. Predictors of virological response to atazanavir in protease inhibitor-experienced patients. HIV Clin Trials. 2004;5(4):201-205.

10. Stebbing J, Nathan B, Jones R, et al. Virological failure and subsequent resistance profiles in individuals exposed to atazanavir. AIDS. 2007;21(13):1826-1828.

11. Cuzin L, Flandre P, Pugliese P, et al. Atazanavir in patients with persistent viral replication despite HAART: Results from the French prospective NADIS cohort. HIV Clin Trials. 2008;9(3):147-151.

12. Shafer R, Schapiro J. HIV-1 drug resistance mutations: An updated framework for the second decade of HAART. AIDS Rev. 2008;10(2):67-84.

13. Lataillade M, Molina JM, Thiry A, Mancini M, McGrath D, for the BMS-AI424138 Study Group. The CASTLE study 48 weeks results: The impact of HIV subtypes and baseline resistance on treatment outcomes and the emergence of resistance. Antivir Ther. 2008;13 suppl 3:A135.

14. Goldsmith D, Perry C. Atazanavir. Drugs. 2003;63(16):1679-93.

15. Colombo S, Buclin T, Cavassini M, et al. Population pharmacokinetics of atazanavir in patients with HIV infection. Antimicrob Agents Chemother. 2006;50(11):3801-3808.

16. Rutstein R, Samson P, Kiser J, et al. The PATCG 1020 protocol: Atazanavir with or without ritonavir in HIV-infected infants, children, and adolescents. 14th Conference on Retroviruses and Opportunistic Infections (CROI). 2007 February 3-5; Los Angeles, USA; Abstract 715.

17. Barreiro $P$, Rodriguez-Novoa $S$, Labarga $P$, et al. Influence of liver fibrosis stage on plasma levels of antiretroviral drugs in HIV-infected patients with chronic hepatitis C. J Infect Dis. 2007;195(7):973-979.

18. Mirochnick M, Capparelli E. Pharmacokinetics of antiretrovirals in pregnant women. Clin Pharmacokinet. 2004;43(15):1071-1087.

19. Eley T, Vandeloise E, Child M, et al. Steady state pharmacokinetics and safety of atazanavir after treatment with ATV $300 \mathrm{mg}$ once daily/ Ritonavir $100 \mathrm{mg}$ once daily + ZDV/3TC during the third trimester in HIV+ women. 15th Conference on Retroviruses and Opportunistic Infections (CROI). 2008 Feb 3-6; Boston, USA; Abstract 624.

20. Ferreira C, Floch-Tudal C, Meier F, et al. Atazanavir in pregnancy: Influence on neonatal hyperbilirubinemia. 15th Conference on Retroviruses and Opportunistic Infections (CROI). 2008 Feb 3-6; Boston, USA; Abstract 625.

21. Lucia M, Golotta C, Rutella S, Rastrelli E, Savarino A, Cauda R. Atazanavir inhibits P-glycoprotein and multidrug resistanceassociated protein efflux activity. J Acquir Immune Defic Syndr. 2005;39(5):635-637.

22. Perloff E, Duan S, Skolnik P, Greenblatt D, von Moltke L. Atazanavir: Effects on P-glycoprotein transport and CYP3A metabolism in vitro. Drug Metab Dispos. 2005;33(6):764-770.
23. La Prote C, Back D, Blaschke T, et al. Updated guidelines to perform therapeutic drug monitoring for antiretroviral agents. Rev Antivir Ther. 2006;3:3-14.

24. Department of Health and Human Services. Guidelines for the use of antiretroviral agents in HIV-1-infected adults and adolescents. January 29, 2008;1-128. [Accessed 31 August 2008]. Available from: http://www.aidsinfo.nih.gov/ContentFiles/AdultandAdolescentGL.pdf

25. Gonzalez de Requena D, Bonora S, Cavechia I. Atazanavir Ctrough is associated with efficacy and safety at 24 weeks: Definition of therapeutic range. 6th International Workshop on Clinical Pharmacology of HIV Therapy. April 28-30 2005; Quebec City, Quebec, Canada; Abstract 60 .

26. Pellegrin I, Breilh D, Ragnaud JM, et al. Virological responses to atazanavir-ritonavir-based regimens: resistance substitutions score and pharmacokinetic parameters (Reyaphar study). Antivir Ther. 2006;11(4):421-429.

27. Morse G, Catanzaro L, Acosta E. Clinical pharmacodynamics of HIV-1 protease inhibitors: Use of inhibitory quotients to optimise pharmacotherapy. Lancet Infect Dis. 2006;6(4):215-225.

28. Winston A, Hales G, Amin J, et al. The normalized inhibitory quotient of boosted protease inhibitors is predictive of viral load response in treatment-experienced HIV-1-infected individuals. AIDS. 2005;19(13):1393-1399.

29. Rodriguez Novoa S, Barreiro P, Rendon A, et al. Plasma levels of atazanavir and the risk of hyperbilirubinemia are predicted by the $3435 \mathrm{C}$ $->\mathrm{T}$ polymorphism at the multidrug resistance gene 1. Clin Infect Dis. 2006;42(2):291-295.

30. Rodriguez-Novoa S, Martin-Carbonero L, Barreiro P, et al. Genetic factors influencing atazanavir plasma concentrations and the risk of severe hyperbilirubinemia. AIDS. 2007;21(1):41-46.

31. Rodriguez-Novoa S, Morello J, González M, et al. Increase in serum bilirubin in HIV/HCV coinfected patients on stable atazanavir therapy following initiation of peginterferon plus ribavirin. AIDS. 2008 (in press).

32. Taburet A, Piketty C, Chazallon C, et al. Interactions between atazanavir-ritonavir and tenofovir in heavily pretreated HIV-infected patients. Antimicrob Agents Chemother. 2004;48(6):2091-2096.

33. Johnson M, Grinsztejn B, Rodriguez C, et al. 96-week comparison of once-daily Atazanavir/ritonavir and twice-daily Lopinavir/ ritonavir in patients with multiple virologic failures. AIDS. 2006;20(5):711-718.

34. Rodriguez-Novoa S, Morello J, Barreiro P, et al. Switch from ritonavirboosted to unboosted atazanavir guided by therapeutic drug monitoring. AIDS Res Hum Retroviruses. 2008;24(6):821-825.

35. Burchell B, Brierley C, Rance D. Specificity of human UDPglucuronosyltransferases and xenobiotic glucuronidation. Life Sci. 1995;57(20):1819-1831.

36. Zhang D, Chando T, Everett D, Patten C, Dehal S, Humphreys W. In vitro inhibition of UDP glucuronosyltransferases by atazanavir and other HIV protease inhibitors and the relationship of this property to in vivo bilirubin glucuronidation. Drug Metab Dispos. 2005;33(11):1729-1739.

37. Hoffmeyer S, Burk O, von Richter O, et al. Functional polymorphisms of the human multidrug-resistance gene: Multiple sequence variations and correlation of one allele with P-glycoprotein expression and activity in vivo. Proc Natl Acad Sci U S A. 2000;97(7):3473-3478.

38. Kroetz D, Pauli-Magnus C, Hodges L, et al. Sequence diversity and haplotype structure in the human ABCB1 (MDR1, multidrug resistance transporter) gene. Pharmacogenetics. 2003;13(8):481-494.

39. Lamba J, Strom S, Venkataramanan R, et al. MDR1 genotype is associated with hepatic cytochrome P450 3A4 basal and induction phenotype. Clin Pharmacol Ther. 2006;79(4):325-338.

40. Kohle C, Mohrle B, Munzel P, et al. Frequent co-occurrence of the TATA box mutation associated with Gilbert's syndrome (UGT1A1*28) with other polymorphisms of the UDP-glucuronosyltransferase-1 locus (UGT1A6*2 and UGT1A7*3) in Caucasians and Egyptians. Biochem Pharmacol. 2003;65(9):1521-1527. 
41. Lankisch T, Moebius U, Wehmeier M, et al. Gilbert's disease and atazanavir: from phenotype to UDP-glucuronosyltransferase haplotype. Hepatology. 2006;44(5):1324-1332.

42. Rotger M, Taffe P, Bleiber G, et al. Gilbert syndrome and the development of antiretroviral therapy-associated hyperbilirubinemia. $J$ Infect Dis. 2005;192(8):1381-1386.

43. Sanne I, Piliero P, Squires K, Thiry A, Schnittman S, AI424-007 Clinical Trial Group. Results of a phase 2 clinical trial at 48 weeks (AI424-007): A dose-ranging, safety, and efficacy comparative tria of atazanavir at three doses in combination with didanosine and stavudine in antiretroviral-naive subjects. $J$ Acquir Immune Defic Syndr. 2003;32(1):18-29.

44. Murphy R, Sanne I, Cahn P, et al. Dose-ranging, randomized, clinical trial of atazanavir with lamivudine and stavudine in antiretroviral-naive subjects: 48-week results. AIDS. 2003;17(18):2603-2614.

45. Gallagher D, Kieran J, Sheehan G, Lambert J, Mahon N, Mallon P. Ritonavir-boosted atazanavir, methadone, and ventricular tachycardia: 2 case reports. Clin Infect Dis. 2008;47(3):e36-8.

46. Busti A, Tsikouris J, Peeters M, et al. A prospective evaluation of the effect of atazanavir on the QTc interval and QTc dispersion in HIVpositive patients. HIV Med. 2006;7(5):317-322.

47. Gianotti N, Guffanti M, Galli L, et al. Electrocardiographic changes in HIV-infected, drug-experienced patients being treated with atazanavir. AIDS. 2007;21(12):1648-1651.

48. Chang H, Pella P. Atazanavir urolithiasis. $N$ Engl J Med. 2006;355(20):2158-2159.

49. Couzigou C, Daudon M, Meynard J, et al. Urolithiasis in HIV-positive patients treated with atazanavir. Clin Infect Dis. 2007;45(8):e105-8.

50. von Hentig N. Atazanavir/ritonavir: A review of its use in HIV therapy Drugs Today (Barc). 2008;44(2):103-132.

51. Malan D, Krantz E, David N, et al. Efficacy and safety of atazanavir, with or without ritonavir, as part of once-daily highly active antiretroviral therapy regimens in antiretroviral-naive patients. J Acquir Immune Defic Syndr. 2008;47:161-167.

52. Hammer S, Eron J, Reiss P, et al. Antiretroviral treatment of adult HIV infection: 2008 recommendations of the international AIDS societyUSA panel. JAMA. 2008;300:555-570.

53. Campbell T, Smeaton L, De Grutolla V, et al. PEARLS (ACTG A5175): A multinational study of didanosine-EC, emtricitabine and atazanavir vs co-formulated ZDV/lamivudine and EFV for initial treatment of HIV-1 infection. XVII International AIDS Conference. 2008 Aug 3-8; Mexico City, Mexico; Abstract THAB0404.

54. Smith K, Weinberg W, Dejesus E, et al. Fosamprenavir or atazanavir once daily boosted with ritonavir $100 \mathrm{mg}$, plus tenofovir/emtricitabine, for the initial treatment of HIV infection: 48-week results of ALERT. AIDS Res Ther. 2008;5:5.

55. Molina J, Andrade-Villanueva J, Echevarria J, et al. Once-daily atazanavir/ritonavir versus twice-daily lopinavir/ritonavir, each in combination with tenofovir and emtricitabine, for management of antiretroviral-naive HIV-1-infected patients: 48 week efficacy and safety results of the CASTLE study. Lancet. 2008;372(9639):646-655.

56. Haas D, Zala C, Schrader S, et al. Therapy with atazanavir plus saquinavir in patients failing highly active antiretroviral therapy: A randomized comparative pilot trial. AIDS. 2003;17(9):1339-1349.

57. Boffito M, Kurowski M, Kruse G, et al. Atazanavir enhances saquinavir hard-gel concentrations in a ritonavir-boosted once-daily regimen. AIDS. 2004;18(9):1291-1297.

58. Cohen C, Nieto-Cisneros L, Zala C, et al. Comparison of atazanavir with lopinavir/ritonavir in patients with prior protease inhibitor failure: A randomized multinational trial. Curr Med Res Opin. 2005;21(10):1683-1692.

59. Johnson M, Grinsztejn B, Rodriguez C, et al. Atazanavir plus ritonavir or saquinavir, and lopinavir/ritonavir in patients experiencing multiple virological failures. AIDS. 2005;19(7):685-694.

60. de Mendoza C, Valer L, Ribera E, et al. Performance of six different ritonavir-boosted protease inhibitor-based regimens in heavily antiretroviral-experienced HIV-infected patients. HIV Clin Trials. 2006;7(4):163-171.
61. Gianotti N, Soria A, Lazzarin A. Antiviral activity and clinical efficacy of atazanavir in HIV-1-infected patients: A review. New Microbiol. 2007;30(2):79-88.

62. Wood R, Phanuphak P, Cahn P, et al. Long-term efficacy and safety of atazanavir with stavudine and lamivudine in patients previously treated with nelfinavir or atazanavir. J Acquir Immune Defic Syndr. 2004;36(2):684-692.

63. Sension M, Grinsztejn B, Molina JM, et al. AI424067: Improvement in lipid profiles after 12 weeks of switching to atazanavir from boosted or unboosted protease inhibitors in patients with no previous PI virologic failure and hyperlipidemia at baseline. 12th Conference on Retroviruses and Opportunistic Infections. 2005 Feb 22-25; Boston, MA, USA; Abstract 858.

64. Bristol-Myers Squibb Company. Clinical Study Report AI424067. [Accessed 31 Aug 2008]. Available from: http://ctr.bms.com/pdf// AI424067.pdf27.

65. Gatell J, Salmon-Ceron D, Lazzarin A, et al. Efficacy and safety of atazanavir-based highly active antiretroviral therapy in patients with virologic suppression switched from a stable, boosted or unboosted protease inhibitor treatment regimen: The SWAN study (AI424-097) 48-week results. Clin Infect Dis. 2007;44(11):1484-1492.

66. Soriano V, Garcia-Gasco P, Vispo E, et al. Efficacy and safety of replacing lopinavir with atazanavir in HIV-infected patients with undetectable plasma viraemia: Final results of the SLOAT trial. J Antimicrob Chemother. 2008;61(1):200-205.

67. Mallolas J, Podzamczer D, Domingo P, et al. Efficacy and safety of switching from lopinavir/r $(\mathrm{LPV} / \mathrm{r})$ to atazanavir/r $(\mathrm{ATV} / \mathrm{r})$ in patients with virologic suppression receiving a LPV/r containing HAART: The ATAZIP study. 4th International AIDS Society Conference on HIV Pathogenesis, Treatment and Prevention. 2007 July 22-25; Sydney, Australia; Abstract WEPEB117LB.

68. Noor M, Flint O, Maa J, Parker R. Effects of atazanavir/ ritonavir and lopinavir/ritonavir on glucose uptake and insulin sensitivity: Demonstrable differences in vitro and clinically. AIDS. 2006;20(14):1813-1821.

69. Guffanti M, Caumo A, Galli L, et al. Switching to unboosted atazanavir improves glucose tolerance in highly pretreated HIV-1 infected subjects. Eur J Endocrinol. 2007;156(4):503-509.

70. Busti A, Bedimo R, Margolis D, Hardin D. Improvement in insulin sensitivity and dyslipidemia in protease inhibitor-treated adult male patients after switch to atazanavir/ritonavir. $J$ Investig Med. 2008;56(2):539-544.

71. Jemsek J, Arathoon E, Arlotti M, et al. Body fat and other metabolic effects of atazanavir and EFV, each administered in combination with ZDV plus lamivudine, in antiretroviral-naive HIV-infected patients. Clin Infect Dis. 2006;42(2):273-280.

72. Haerter G, Manfras B, Mueller M, Kern P, Trein A. Regression of lipodystrophy in HIV-infected patients under therapy with the new protease inhibitor atazanavir. AIDS. 2004;18(6):952-955.

73. Moyle G, Girard J, Andrade J, et al. Continuation of BID boosted PI vs switch to once-daily ATV/RTV for the management of lipodystrophy: 48 week primary analysis of the 96 week multicenter, open-label, randomized, prospective ReAL study. XVII International AIDS Conference. 2008 August 3-8; Mexico City, Mexico; Abstract MOPDB103.

74. Colafigli M, Di Giambenedetto S, Bracciale L, Tamburrini E, Cauda R, De Luca A. Cardiovascular risk score change in HIV-1-infected patients switched to an atazanavir-based combination antiretroviral regimen. HIV Med. 2008;9(3):172-179.

75. Flammer A, Vo N, Ledergerber B, et al. Effect of atazanavir versus other protease inhibitor-containing antiretroviral therapy on endothelial function in HIV-infected persons: Randomized controlled trial. Heart (in press).

76. Arribas JR, Pulido F, Delgado R, et al. Lopinavir/ritonavir as single-drug therapy for maintenance of HIV-1 viral suppression: 48-week results of a randomized, controlled, open-label, proof-ofconcept pilot clinical trial (OK study). J Acquir Immune Defic Syndr. 2005;40(3):280-287. 
77. Pulido F, Arribas JR, Delgado R, et al. Lopinavir-ritonavir monotherapy versus lopinavir-ritonavir and two nucleosides for maintenance therapy of HIV. AIDS. 2008;22(2):F1-9.

78. Swindells S, DiRienzo AG, Wilkin T, et al. Regimen simplification to atazanavir-ritonavir alone as maintenance antiretroviral therapy after sustained virologic suppression. JAMA. 2006;296(7):806-814.

79. Karlstrom O, Josephson F, Sonnerborg A. Early virologic rebound in a pilot trial of ritonavir-boosted atazanavir as maintenance monotherapy. J Acquir Immune Defic Syndr. 2007;44(4):417-422.

80. Vernazza P, Daneel S, Schiffer V, et al. The role of compartment penetration in PI-monotherapy: The atazanavir-ritonavir monomaintenance (ATARITMO) trial. AIDS. 2007;21(10):1309-1315.
81. Sahali S, Chaix ML, Delfraissy JF, Ghosn J. Ritonavir-boosted protease inhibitor monotherapy for the treatment of HIV-1 infection. AIDS Rev. 2008;10(1):4-14.

82. Vora S, Marcelin AG, Gunthard H, et al. Clinical validation of atazanavir/ritonavir genotypic resistance score in protease inhibitorexperienced patients. AIDS. 2006;20(1):35-40.

83. Bertoli A, Santoro MM, Lorenzini P, et al. Different patterns of mutations involved in the genotypic resistance score for atazanavir boosted versus atazanavir unboosted in multiply failing patients. Antivir Ther. 2006;11 suppl 1:S99. 